\title{
Hazard Elimination Procedures for Leaded Paints in Housing
}

U.S.
ARTMENT
OF
MMERCE
National
Rureau
P- of
00 rds
153
770
73


The National Bureau of Standards ${ }^{1}$ was established by an act of Congress March 3, 1901. The Bureau's overall goal is to strengthen and advance the Nation's science and technology and facilitate their effective application for public benefit. To this end, the Bureau conducts research and provides: (1) a basis for 'the Nation's physical measurement system, (2) scientific and technological services for industry and government, (3) a technical basis for equity in trade, and (4) technical services to promote public safety. The Bureau consists of the Institute for Basic Standards, the Institute for Materials Research, the Institute for Applied Technology, the Center for Computer Sciences and Technology, and the Office for Information Programs.

THE INSTITUTE FOR BASIC STANDARDS provides the central basis within the United States of a complete and consistent system of physical measurement; coordinates that system with measurement systems of other nations; and furnishes essential services leading to accurate and uniform physical measurements throughout the Nation's scientific community, industry, and commerce. The Institute consists of a Center for Radiation Research, an Office of Measurement Services and the following divisions:

Applied Mathematics - Electricity - Mechanics - Heat - Optical Physics Linac Radiation ${ }^{2}$ - Nuclear Radiation ${ }^{2}$ - Applied Radiation ${ }^{2}$ - Quantum Electronics" - Electromagnetics" - Time and Frequency ${ }^{3}$ - Laboratory Astrophysics : - Cryogenics ${ }^{3}$.

THE INSTITUTE FOR MATERIALS RESEARCH conducts materials research leading to improved methods of measurement, standards, and data on the properties of well-characterized materials needed by industry, commerce, educational institutions, and Government; provides advisory and research services to other Government agencies; and develops, produces, and distributes standard reference materials. The Institute consists of the Office of Standard Reference Materials and the following divisions:

Analytical Chemistry-Polymers-Metallurgy-Inorganic Materials-Reactor Radiation-Physical Chemistry.

THE INSTITUTE FOR APPLIED TECHNOLOGY provides technical services to promote the use of available technology and to facilitate technological innovation in industry and Government; cooperates with public and private organizations leading to the development of technological standards (including mandatory safety standards), codes and methods of test; and provides technical advice and services to Government agencies upon request. The Institute also monitors NBS engineering standards activities and provides liaison between NBS and national and international engineering standards bodies. The Institute consists of a Center for Building Technology and the following divisions and offices:

Engineering and Product Standards-Weights and Measures-Invention and Innovation-Product Evaluation Technology-Electronic Technology-Technical Analysis-Measurement Engineering-Building Standards and Code Services ${ }^{4}$-Housing Technology ${ }^{4}$-Federal Building Technology ${ }^{4}$-Structures, Materials and Life Safety ${ }^{4}$-Building Environment ${ }^{4}$-Technical Evaluation and Application ${ }^{4}$-Fire Technology.

THE INSTITUTE FOR COMPUTER SCIENCES AND TECHNOLOGY conducts research and provides technical services designed to aid Government agencies in improving cost effectiveness in the conduct of their programs through the selection, acquisition, and effective utilization of automatic data processing equipment; and serves as the principal focus within the executive branch for the development of Federal standards for automatic data processing equipment, techniques, and computer languages. The Center consists of the following offices and divisions:

Information Processing Standards-Computer Information-Computer Services -Systems Development-Information Processing Technology.

THE OFFICE FOR INFORMATION PROGRAMS promotes optimum dissemination and accessibility of scientific information generated within NBS and other agencies of the Federal Government; promotes the development of the National Standard Reference Data System and a system of information analysis centers dealing with the broader aspects of the National Measurement System; provides appropriate services to ensure that the NBS staff has optimum accessibility to the scientific information of the world, and directs the public information activities of the Bureau. The Office consists of the following organizational units:

Office of Standard Reference Data-Office of Technical Information and Publications-Library-Office of International Relations.

\footnotetext{
1 Headquarters and Laboratories at Gaithersburg, Maryland, unless otherwise noted; mailing address Washington, D.C, 20234 .

2 Part of the Center for Radiation Research.

socated at Boulder, Colorado 80302.

- Part of the Center for Bullding Technology.
} 


\section{$\cdots 1$

David Waksman

Office of Housing Technology

and

Leopold F. Skoda and Elizabeth J. Clark

Structures, Materials, and Life Safety Division

Center for Building Technology

Institute for Applied Technology

National Bureau of Standards

Washington, D.C. 20234

$$
\text { tTechnecal note no. } 970
$$

Sponsored by

The Department of Housing and Urban Development

Washington, D.C. 20410

NBS Technical Notes are designed to supplement the Bureau's regular publications program. They provide a means for making available scientific data that are of transient or limited interest. Technical Notes may be listed or referred to in the open literature.

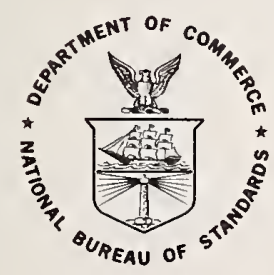

\section{U.S. DEPARTMENT OF COMMERCE, Frederick B. Dent, Secretary} NATIONAL BUREAU OF STANDARDS, Richard W. Roberts, Director Issued May 1973 
National Bureau of Standards Technical Note 770

Nat. Bur. Stand. (U.S.), Tech. Note 770, 99 pages (May 1973)

CODEN: NBTNAE

For sale by the Superintendent of Documents, U.S. Government Printing Office, Washington, D.C. 20402 (Order by SD Catalog No. C13.46:770).

Price $\$ 1.25$ donestic postpaid or $\$ 1.00$ G.P.O. Bookstore 
1. Introduction . . . . . . . . . . . . . 1

2. Hazard Elimination Procedures . . . . . . . . 3

3. Analyses of Hazard Elimination Methods for Leaded Paints . . 5

3.1. General .............. 5

3.2. Attributes ............ 5

3.2.1. General Discussion ........... 5

3.2.2. Hazard Inaccessibility ......... 8

3.2.3. Special Preconditions . . . . . . . . 10

3.2.4. Installation Health and Safety ....... 10

3.2.5. Ancillary Work ............ 11

3.2.6. Waste Disposal ............ 11

3.2.7. Community Involvement . . . . . . . . 11

3.2.8. Occupant Involvement .......... 11

3.2.9. Degree of Finish . . . . . . . . . 12

3.2.10. Performance ........... 12

3.2.10.1. Occupant Health and Safety . . . 12

3.2.10.2. Durability and Stability ..... 12

3.2.10.3. Acceptability . . . . . . 13

3.3. Hazard Elimination Matrices . . . . . . . . 14

3.3.1. General Considerations . . . . . . . . 14

3.3.2. Matrix I: Removal Methods......... 15

3.3.2.1. Definitions ......... 15

3.3.2.2. Preliminary Considerations . . . . 17

3.3.3. Matrix II: Surface Repair Methods . . . . . 20

3.3.4. Matrix III: Cover Up - Unfinished Membrane

Material ........... 22

3.3.5. Matrix IV: Cover Up - Unfinished Rigid

Material . . . . . . . . . 24

3.3.6. Matrix V: Cover Up - Prefinished Rigid

Material ............ 26

3.3.7. Matrix VI: Surface Finish Methods . . . . 28

4. Materials Selector Guide . . . . . . . . . . 31 
5. Summary of Hazard Elimination Procedures . . . . . . . . 33

5.1. Preliminary Considerations . . . . . . . . 33

5.2. Hazard Potential ............ . . 34

5.3. Currently Available Methods .......... . 36

5.4. Properties of Hazard Elimination Systems . . . . . . 40

6. References ................. . . 42

Appendix A - Hazard Elimination Considerations . . . . . . . A Al

A.1. Hazard Inaccessibility ............... Al

A.2. Special Preconditions ............... A8

A.3. Installation Health and Safety .......... Al8

A.4. Ancillary Work ............... A20

A.5. Waste Disposal .............. A25

A.6. Community Involvement . . . . . . . . . . . A25

A.7. Occupant Involvement ............. A26

A.8. Degree of Finish . . . . . . . . . . A26

A.9. Performance: Health and Safety .......... A27

A.9.1. Fire Resistance .............. A27

A.9.2. Toxicity ............. A28

A.9.3. Spatial Factors . . . . . . . . . . A28

A.9.4. Vermin Resistance . . . . . . . . . . . A28

A.9.5. Mold Growth Resistance . . ......... A31

A.9.6. Dirt Collection Resistance ......... A32

A.10. Performance: Durability and Stability ........A32

A.10.1. Structural Integrity . . . . . . . . A32

A.10.2. Scrape Adhesion . . . . . . . . . A32

A.10.3. Impact Resistance . . . . . . . . . . A34

A.10.4. Abrasion Resistance . . . . . . . . . A35

A.10.5. Moisture Resistance . . . . . . . . A35 
A.10.6. Vibration Resistance . . . . . . . . . A36

A.10.7. Colorfastness . . . . . . . . . . . . A37

A. 10.8. Aging Resistance .. . . . . . . . . . . A37

A.10.9. Adhesion of Leaded Paint . . . . . . . . . . A38

A.10.10. Adhesive Durability and Stability . . . . . . A40

A.11. Performance: Acceptability . . . . . . . . . . . A43

A.11.1. Washability . . . . . . . . . . . A43

A.11.2. Maintainability of the Surface . . . . . . . A44

A.11.3. Acoustic Properties . . . . . . . . . . . A46

A.11.4. Color Reflectance . . . . . . . . . . . A46

A.11.5. Attachment Capability . . . . . . . . . A48

A.11.6. Appearance . . . . . . . . . . . A48

A. 12. References . . . . . . . . . . . . . . . . A49

List of Tables

$\underline{\text { Page }}$

1. Average Height and Reach of Children . . . . . . . . . . 9

2. Materials Selector Guide for Covering Leaded Paints on

Walls and Ceilings . . . . . . . . . . . . . .

A-1 Flame Spread Rating Limitations of Interior Finishes . . • . . A29

A-2 Evaluation of Adhesion with Balanced Beam Scrape Adhesion

Tester . . . . . . . . . . . . . . . . . .

A-3 Classification of Sound Insulating Properties of Partitions According to Their Average Transmission Loss . . . . . . . . 
I. Decision Model - Part I . . . . . . . . . . . . 6

II. Decision Model - Part II . . . . . . . . . . . . 7

III. Matrix I - Removal Methods . . . . . . . . . . . . 16

IV. Matrix II - Surface Repair Methods . . . . . . . . . . 21

V. Matrix III - Cover Up - Unfinished Membrane Material • . . 23

VI. Matrix IV - Cover Up - Unfinished Rigid Materia1 • • • . 25

VII. Matrix V - Cover Up - Prefinished Rigid Material • • • . 27

VIII. Matrix VI - Surface Finish Methods . . . . . . . . . . 29

Acknowledgment

The authors thank Mr. McClure Godette of the National Bureau of Standards for making recommendations for the performance of finished surfaces. Sincere thanks are due also to Mr. Roger H. Higgons of the National Paint and Coatings Association and Mr. David E. Brackett of the Gypsum Association for their many helpful comments. The work of Mr. David B. Hattis, formerly of the National Bureau of Standards, on the development of a methodology for the evaluation of hazard elimination methods is also gratefully adknowledged. 
Hazard Elimination Procedures for Leaded Paints in Housing David Waksman, Leopold F. Skoda and Elizabeth J. Clark

Methods currently used to control the hazard caused by leaded paints in housing vary in effectiveness from complete elimination of the hazard to a minimal effort that runs a high risk for recurrence of the hazard. A series of guidelines has been drawn up to acquaint municipal planners and other decision makers with the factors that should be considered in implementing a hazard elimination program. Formats are presented to describe attributes of the various methods that should be considered.

Key words: Building materials; housing; leaded paint; lead hazard elimination methods; lead paint poisoning; performance attributes.

\section{Introduction}

Childhood lead poisoning is a problem that has been facing health departments and building officials for many years. The magnitude of this problem on a nationwide basis has only recently been realized. It has been estimated that more than 600,000 children in the United States have dangerous levels of lead in their blood [1]*

* Figures in brackets indicate references given on page 42 . 
According to Lin Fu [2], "In children, lead poisoning results almost exclusively from ingestion of flaking and peeling lead-containing paints found in old houses and on old furniture." Loose paint and paint adhered to surfaces that can be chewed are two of the most common sources of leaded paint that are accessible to children.

This publication is intended to meet the growing need for information about the various building materials and techniques that are currently available to make leaded paint in housing inaccessible to children. It is hoped that this report will promote the effective utilization of the resources that are available to combat the problem.

The problem of dealing with lead poisoning from paints is compounded by the fact that each residence must be treated separately. The location of the hazard will vary widely from dwelling unit to dwelling unit. Similar variances in architectural configuration and degree of deterioration will also occur. Procedures, therefore, must be carefully matched with the conditions found in each housing unit.

There has been a considerable amount of confusion about what actually constitutes a hazard. The presence of lead above a given level in paint ( $1 \%$ in most cases) does not by itself mean that a Jead hazard is present. It is a necessary, but not a sufficient condition. The paint is only hazardous if it is accessible to children. To try to eliminate this confusion the National Bureau of Standards (NBS) has defined four different hazard conditions in terms of the accessibility of leaded materials to children. (See sec. 3.1.)

Methods that are currently available to eliminate the hazard presented by leaded materials in each of these conditions are discussed in 
terms of properties that should be considered when choosing a procedure for elimination of the problem.

In addition to the primary requirement of hazard inaccessibility that every solution to the problem should meet, several secondary properties were considered. These properties are related either to work involved in the implementation of hazard elimination procedures, or to the performance of surfaces after work has been completed. (See sec. 3.2. for more detailed information.)

\section{Hazard Elimination Procedures}

The three basic procedures that can be used to eliminate the exposure of children to leaded paint in housing are: (1) keeping the children out of such housing, (2) removing the hazardous material, and (3) covering up the hazardous material with an effective barrier to make it inaccessible. When children are present, only complete removal or covering up of a11 leaded paint will render a residence totally safe.

Paint can be removed by sanding or scraping. Paint removers or heat softening to loosen tightly adhered paint can be used in conjunction with scraping. Covering materials that can be used include rigid materials such as gypsum board, hardboard, and plywood. Membrane type materials such as fabrics, liquid coatings, wallpaper, and veneer plaster can be used to cover up leaded paint only if the surfaces to be covered are in good condition. Removal and cover up hazard elimination procedures will be discussed in detail in section 3.3. of this paper.

Several other methods of unproven value have also been suggested as solutions to the problem. The most widely known of these is the inclu- 
sion of a bad tasfing substance in a paint which is then used to cover existing lead bearing paint surfaces. The theory behind this method is that the bad taste will discourage the child from eating paint chips. There is no direct evidence available to show that this approach is effective.

A similar approach, using a paint containing an emetic to cover the lead-bearing painted surfaces has also been suggested. The effectiveness of this method has not yet been proven.

Covering existing painted surfaces that contain lead with a paint containing a chelating agent has also been proposed as a solution to the problem. In theory, the chelating agent would react with the lead and put it in a form that could be readily eliminated from the child's system. Although the use of chelating agents in controlled amounts is an accepted medical procedure, their use in the above mentioned uncontrolled manner could be hazardous. According to Chisolm [3], "Chelating agents should not be administered orally in the presence of continued hazardous exposure. Oral EDTA increases the absorption of lead from the intestine." In summary, only two hazard elimination procedures are known to be effective: completely removing all the leaded material, or covering it up with an effective barrier. The ideal solution to the problem would be to render all leaded materials in all housing inaccessible to children. However, when limited funds are available and it is not possible to completely eliminate the hazard, compromises may have to be made. A typical compromise solution would be the removal of all loose and peeling leaded material, and tightly adhered leaded material on chewable surfaces, leaving all other leaded material intact. 
3. Analyses of Hazard Elimination Methods for Leaded Paints

\subsection{General}

A Decision Model, prepared by NBS, defines four levels or conditions of hazard accessibility and presents the options that are available to deal with the paint problem. These conditions, which are outlined in figure I, are indicative of the immediacy of the threat presented by leaded materials that can be found in housing.

Figure II illustrates the various procedures that are available for the treatment of housing, and also serves as an index to detailed matrices relating specific procedures to their attributes (i.e., inherent characteristics).

The Decision Model is the first part of a system designed to acquaint local decision makers with factors that should be considered when selecting and evaluating methods for hazard elimination.

The second part of the system consists of a series of six detailed matrices relating specific hazard elimination techniques to their attributes. Methods considered include: paint removal, surface repair, covering up with both rigid and membrane-type materials (prefinished and unfinished), and the finishing of surfaces.

\subsection{Attributes}

\subsubsection{General Discussion}

As was previously stated, the primary attribute required of every, method is that is render the hazardous material inaccessible. Success in complying with this requirement is dependent both on the method of hazard removal and the extent to which it is implemented. 


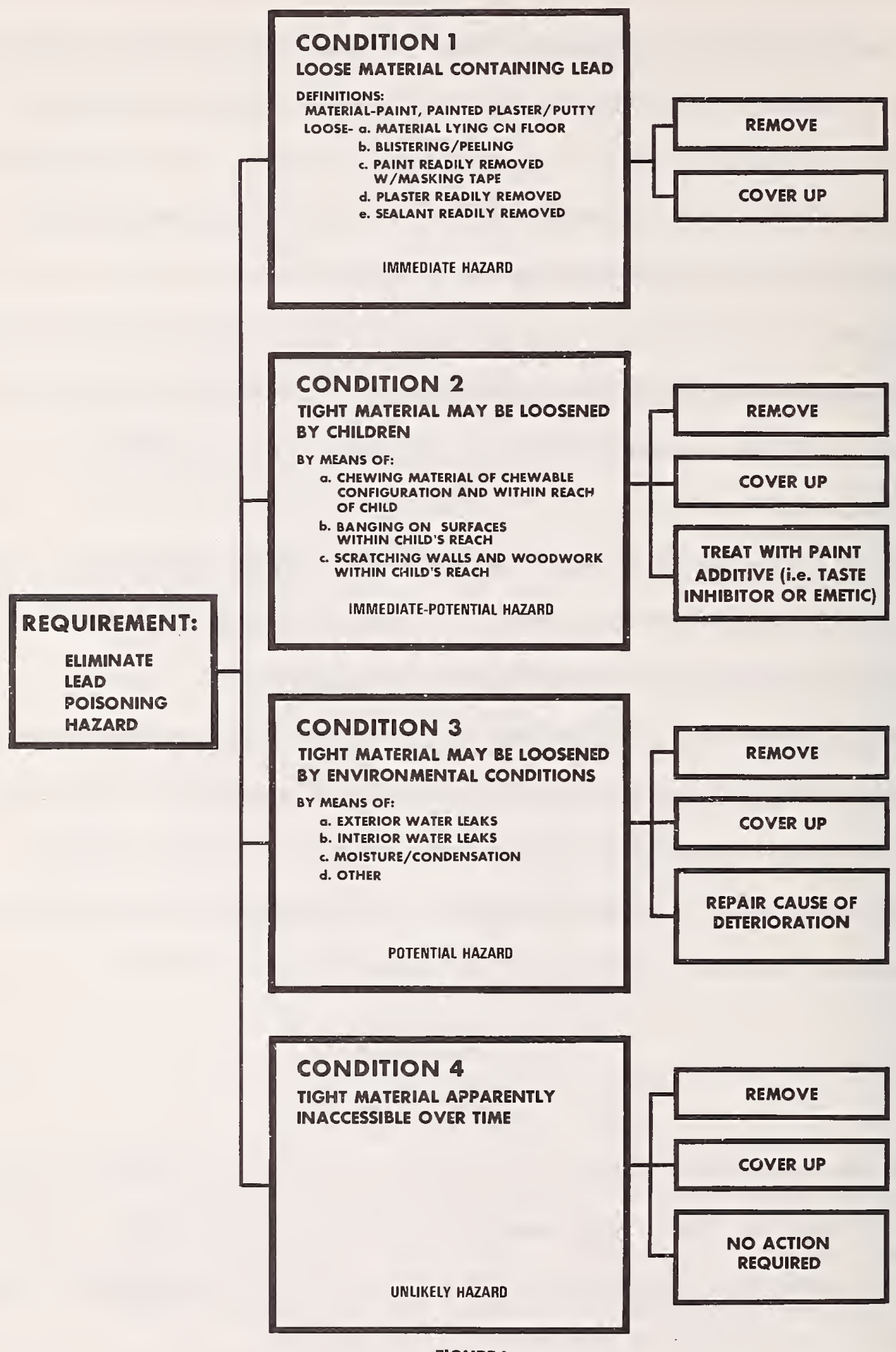

FIGURE I 

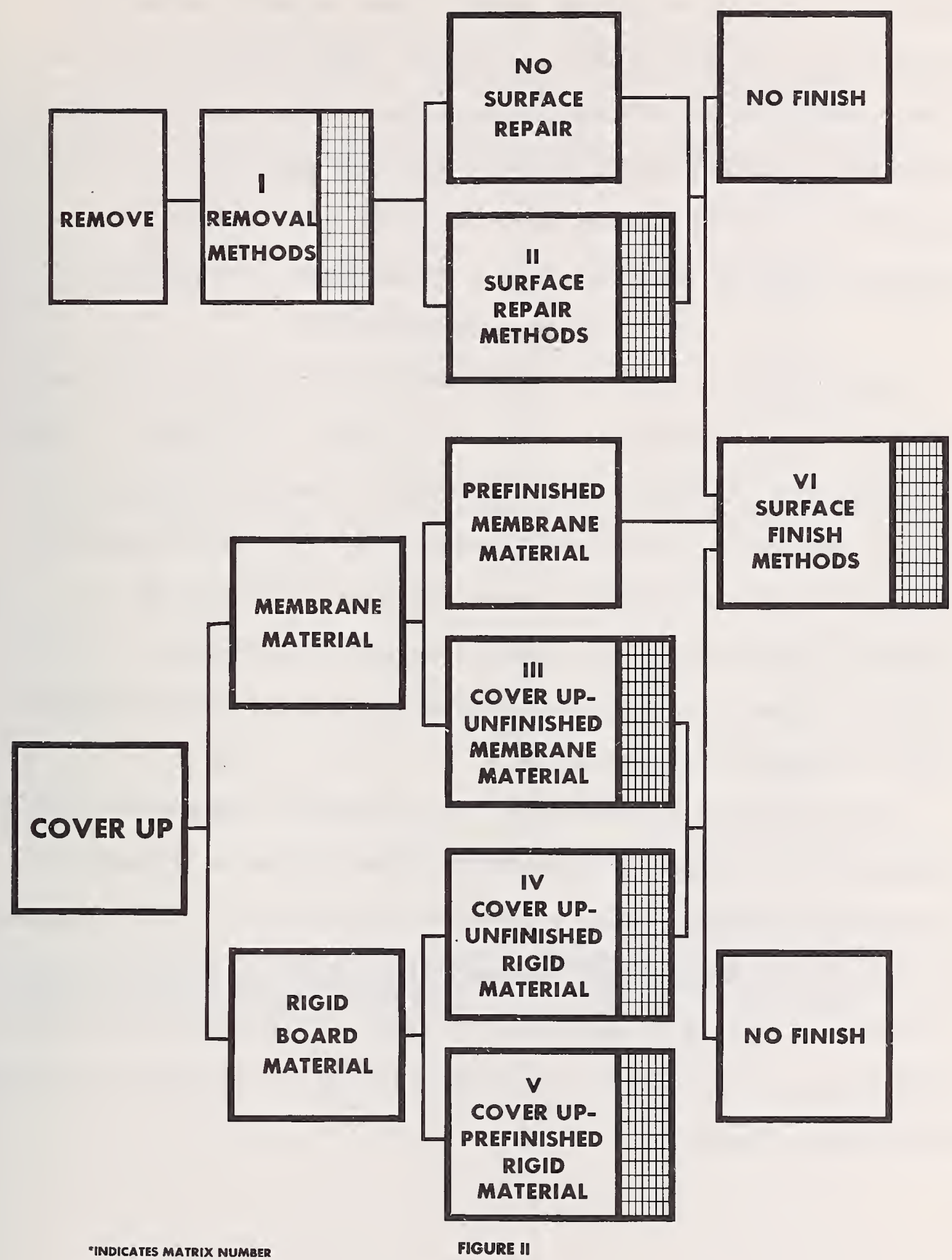
The many secondary properties that are inherent parts of specific procedures should be considered carefully when selecting methods to eliminate the lead paint poisoning problem. These characteristics include factors such as the health of both the occupant and the workers, the potential for recurrence of the problem, the degree of rehabilitation obtained, etc. Detailed discussions of hazard inaccessibility and secondary properties that were felt to be important are given below.

\subsubsection{Hazard Inaccessibility}

Accessibility of residual leaded material is related to both the degree of hazard elimination and the method used. For example: if only loose 1 eaded material and leaded material from chewable surfaces are removed, then access to the remaining leaded material can be gained by (a) loosening of tight material by the actions of children and (b) loosening of tight material by natural causes such as moisture. If a covering is used that can be torn away the hazardous material beneath it may once again become accessible.

The forces that children exert and the heights to which they may reach should be considered to ensure the effectiveness of a hazard elimination procedure. Table 1 presents the height of a chewable surface and the distance that a child can reach when standing on the floor as a function of the age of the child. It must be remembered that children often stand on objects such as bunk beds, tables or sofas that can extend their height of reach. 
Table 1

Average Height and Reach of Children*

\begin{tabular}{|c|c|c|c|c|}
\hline $\begin{array}{c}\text { Age } \\
\text { Years } \\
\end{array}$ & 昷eight & Span & $\begin{array}{c}\text { Reach } \\
(\text { Height }+ \\
25 \% \text { Span) } \\
\end{array}$ & $\begin{array}{c}\text { Chewable } \\
\text { Surface } \\
\text { (Height) }-(6 \text { inches }) \\
\end{array}$ \\
\hline 6 & 45.0 & 44.0 & 56.0 & 39.0 \\
\hline 5 & 42.7 & 41.4 & 53.1 & 36.7 \\
\hline 4 & 40.2 & 38.8 & 49.9 & 34.2 \\
\hline 3 & 37.3 & 36.2 & 46.4 & 31.3 \\
\hline 2 & 33.9 & 32.7 & 42.1 & 27.9 \\
\hline 1 & 29.5 & 28.3 & 36.6 & 23.5 \\
\hline 6 & 44.6 & 43.3 & 55.4 & 38.6 \\
\hline 5 & 42.2 & 40.7 & 52.4 & 36.2 \\
\hline 4 & 39.6 & 38.1 & 49.1 & 33.6 \\
\hline 3 & 36.7 & 35.1 & 45.5 & 30.7 \\
\hline 2 & 33.4 & 32.1 & 41.4 & 27.4 \\
\hline 1 & 29.0 & 27.7 & 35.9 & 23.0 \\
\hline
\end{tabular}

* All values are in inches as converted from The Harriet Lane Handbook A Manual for Pediatric House Officers, Johns Hopkins Hospital, 5 th Edition, Year Book Medical Pulbishers, Inc., Chicago, Ill., 1969. 
It has been estimated that a five year old may be able to push and pull with a force greater than 40 pounds [4], and to bite exerting a force of 100-300 pounds with a bite reach of 1 to 1.5 inches [5]. Very little is known about the forces that a child may exert by kicking, pounding, or gouging, although they should be known to set minimum standards for materials used in hazard elimination. However, since a determined child can pound, hammer, or bang his way through almost anything, it would not be practical to require a child-proof material.

\subsubsection{Special Preconditions}

Certain conditions are required before many hazard removal techniques can be implemented; e.g., if a facing is to be put up with an adhesive, all loose material should be removed from the surface to be covered, and the surface must be free of moisture, oil, dirt, etc. If rigid boards are to be applied, there are certain support requirements for the boards such as the degree of planarity, support spacings, etc.

\subsubsection{Installation Health and Safety}

Many available hazard elimination techniques have health problems associated with them. The following are typical examples of problems created by removal procedures. Removing leaded paints by sanding creates a highly toxic, fine, leaded dust; softening leaded paint with an open flame can give rise to lead fumes in addition to presenting a fire hazard; cutting various board materials may give rise to dust that can be injurious. 


\subsubsection{Ancillary Work}

Some deleading procedures may require additional work to be done in conjunction with them; e.g., putting up wall board may require the relocation of plumbing, electrical, and heating fixtures.

\subsubsection{Waste Disposal}

When leaded wastes are generated in the course of hazard removal, care should be taken to ensure that they are disposed of in a manner that will render them inaccessible to children. Other waste materials should also be disposed of in such a manner that they do not present a hazard.

\subsubsection{Community Involvement}

Since available funds for hazard elimination may be 1 imited, certain advantages can be gained by selecting hazard removal methods that lend themselves to the use of semiskilled and unskilled 1abor. Considerable cost savings can be realized by utilizing self-help labor and the skills gained in the course of carrying out a community action program can be carried over to the 1 abor market.

\subsubsection{Occupant Involvement}

Some techniques will require the relocation of occupants from a residence because of the hazards involved. Other methods require only temporary dislocation from a room. Since the costs of relocation can be quite high, it is desirable to choose procedures that do not require moving the residents of a dwelling. 


\subsubsection{Degree of Finish}

Some techniques, such as scraping, leave the dwelling surfaces in a crude, unfinished state unless further finish work is done. Other methods, e.g., prefinished panels, provide an inherent finished surface.

\subsubsection{Performance}

In general, consideration of performance properties should be limited to completely finished systems and not individual elements. When performance is evaluated, a complete system that includes the provision of adequate supports and a protective surface finish should be considered.

Properties that should be reviewed when evaluating the performance of hazard elimination methods are listed below.

\subsubsection{Occupant Health and Safety*}

\section{Fire Resistance}

2. Toxicity

3. Spatial Factors

4. Vermin Resistance

5. Mold Growth Resistance

6. Dirt Collection Resistance

\subsubsection{Durability and Stability*}

1. Structural Integrity

2. Scrape Adhesion

3. Impact Resistance

4. Abrasion Resistance

5. Moisture Resistance

* See Appendix A for further information about these properties. 
6. Vibration Resistance

7. Colorfastness

8. Aging Resistance

9. Adhesion of Leaded Paint

10. Adhesive Durability and Stability

\subsubsection{Acceptability*}

1. Washability

2. Maintainability of the Surface

3. Acoustic Properties

4. Color and Reflectance

5. Attachment Capability

6. Appearance

Although not all of the properties listed above are usually covered by local codes, they should still be considered in the selection of hazard elimination methods. Where properties are covered by local codes, these code requirements should be complied with. Specific test procedures and recommended minimum performance levels are presented for these properties in Appendix A, Hazard Elimination Consideration. Detailed matrices presented in section 3.3. relate these properties to specific procedures.

Typical examples of performance requir ements that should be met to ensure hazard inaccessibility are listed below.

* See Appendix A for further information about these properties. 
When a substrate with tightly adhered paint is required for the satisfactory performance of a hazard elimination method, the requirements specified for Adhesion of Leaded Paint (Appendix A, Performance: Durability and Stability, A.10.9.) should be met.

Adhesives used for the application of covering materials should comply with the requirements specified for Adhesive Durability and Stability (Appendix A, Performance: Durability and Stability, A.10.10.).

Systems used as a barrier to leaded paint in areas within the reach of children should meet the requirements specified for Impact Resistance (Appendix A, Performance: Durability and Stability, A.10.3.).

\subsection{Hazard Elimination Matrices}

\subsubsection{General Considerations}

This section describes specific procedures and presents them in matrix form. The matrices, which are referred to in figure II also outline attributes of methods and materials used for hazard elimination. Methods and materials are 1 isted along the vertical axis while properties (attributes) are along the horizontal axis.

The indexing numbers given in the boxes that represent the intersections between the method or material rows and the attribute columns refer to detailed analyses given in Appendix A. These analyses are grouped into sections by means of the attributes that were discussed 
in section 3.2. For example, the numeral 1, given in the Hazard Inaccessibility column of figure III, refers to write-up number $\mathbb{1}$ in the Hazard Inaccessibility section of Appendix A. The numerals 2, 5, and 7 given in the box that represents the intersection between the Scrape-No Softening row and the Installation Health and Safety column refer to write-ups 2, 5, and 7 of the Installation Health and Safety section of Appendix A.

Since reliable, detailed data were not available, time and cost factors were not considered. It is hoped that this information will be available in the future. Figures that are indicative of typical costs for the installation of covering materials on previously prepared surfaces are shown in tab1e 2 .

\subsubsection{Matrix I: Removal Methods}

\section{(See figure III.)}

\subsubsection{Definitions}

A. Sanding - Removal of leaded paint by abrasion using either hand operated or mechanical means applied to all surfaces or to selected portions, e.g., woodwork. (It is frequently used to remove small amounts of residual paint present after other removal methods have been implemented. Roughening of surfaces by sanding can result in improved adhesion for subsequently applied covering materials.)

B. Scraping with No Softening - Hand scraping using a putty knife or similar instrument to remove loose paint. 


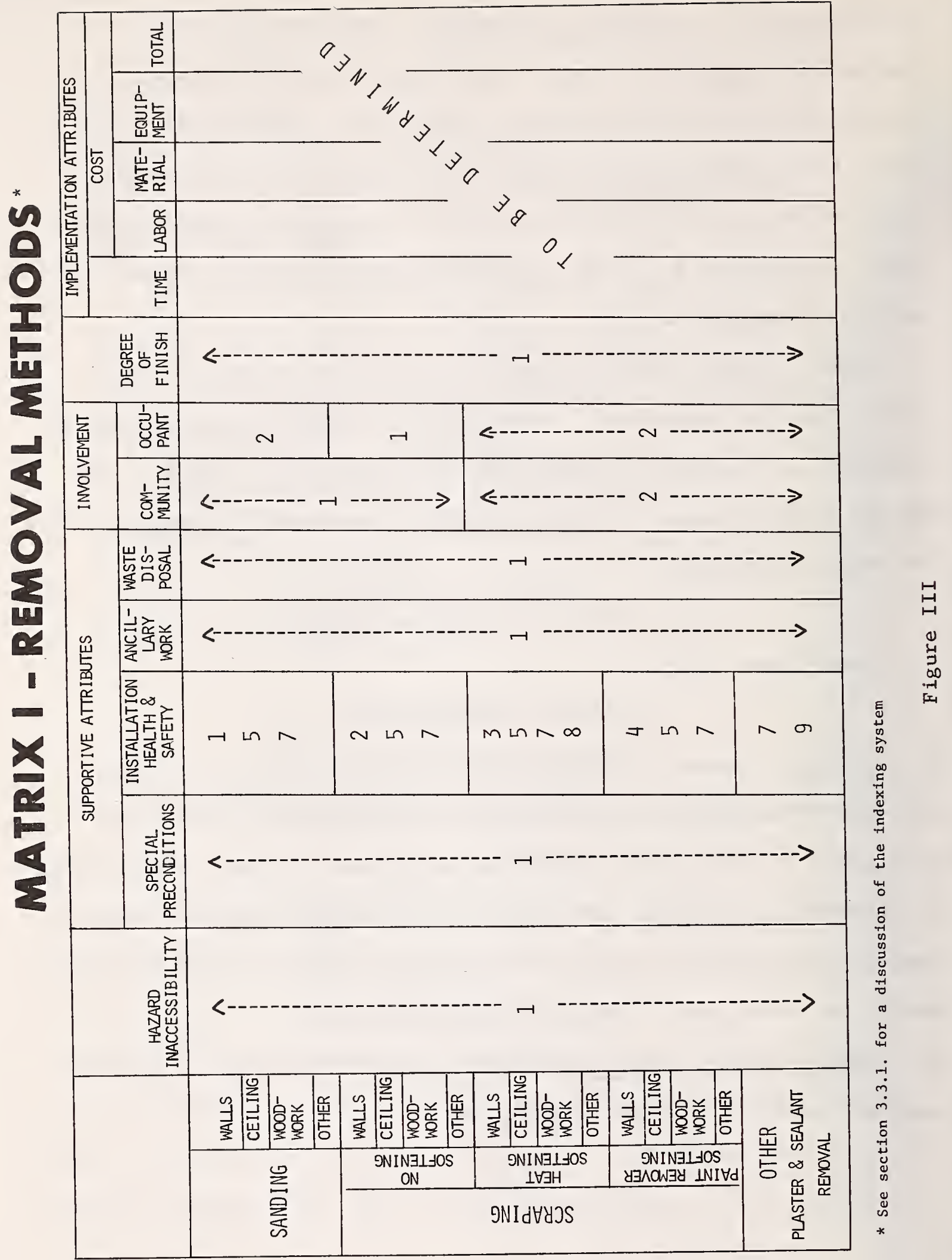


C. Scraping with Heat Softening - Preliminary softening of paint by means of heat (open flame or high intensity heat 1 amps) followed by scraping, or a combined heating and scraping operation with electric scrapers. (This is applicable to tightly adhered paint.)

D. Scraping with Paint Removers - Preliminary softening of paint by chemical means, followed by subsequent scraping. (This is applicable to tightly adhered paint.)

\subsubsection{Preliminary Considerations}

Several approaches may be followed when old paint must be removed from surfaces presenting a lead poisoning hazard. Since each method has its limitations and hazards, the following comments are offered for guidance to the personnel responsible for selecting paint removal methods. Use of Paint Removers

It can be assumed that most.liquids of this type are flammable and/ or give off harmful vapors when used. Any such hazards should be made known by appropriate warnings on the 1 abels of their containers.

Methylene chloride is a primary ingredient of some of the newer types of paint removers. Its fumes, while less toxic than those of some other solvents used in removers, are sufficiently irritating to require ample ventilation. Most products that do not contain substantial amounts of methylene chloride are combustible, and usually contain aromatic hydrocarbons or other solvents that can be harmful if concentrated vapors are inhaled for a prolonged period. 
The use of volatile solvent type removers on interior surfaces of dwellings may be very undesirable, particularly when they are occupied, if the materials are flammable or toxic. Thus, removers are useful mainly for components such as doors and windows that can be taken outdoors for treatment. The manufacturer's directions for use of the remover chosen should be followed closely to avoid hazards.

When certain organic-based removers are used, the surfaces must be washed thoroughly with a solvent such as turpentine after the paint is scraped off in order to remove waxy residues left by the remover [6]. If this is not done, poor adhesion of subsequently applied paint can result. Some removers, such as those of the "water-wash" type, generally contain methylene chloride as the principal solvent and frequently do not contain waxy material. When surfaces are washed clean with water after scraping off paint they must be allowed to dry thoroughly before repainting. Since water-washing tends to raise the grain of wood, some light sanding is usually necessary. The manufacturer's recommendations for use of the particular product selected should be closely followed to avoid residues.

\section{"Burning" (Heat Softening)}

Burning and scraping to remove old paint is a traditional method; however, some cities will not permit the use of an open flame for interior work due to the fire hazard created by this technique. Other cities permit open flame use if adequate fire extinguishing equipment is available. Enclosed high-temperature heat 1 amps that have recently been developed are claimed both to be effective and to eliminate the fire hazard. The ease of paint removal by burning depends on several 
factors including the age and thickness of the paint film, the type of vehicle present in the old paint, and the degree of pigmentation of the paint film. The older types of paint, which used a high amount of 1 inseed oil vehicle, and most enamels, soften fairly readily under heat, whereas old, highly-pigmented flat paints are more heat resistant. It is easier to burn paint off wood surfaces than from plaster or masonry. Burning is not recommended for wallboard substrates because of the damage that can occur to the substrate during paint removal.

\section{Mechanical Removal}

Hand scraping with a putty knife or special paint scraper is effective for removing loose and semi-loose paint. Care must be taken to use the tool in such a manner that the edge of the blade gets under the paint film, otherwise it can ride on top and fail to remove semi-loose paint that will then peel after repainting. Rotary power tools that are now available work much faster than hand tools. They are suitable for applications where they will not damage the substrate.

Sanding with hand or power tools is also effective for smaller areas but produces a great deal more dust than scraping. Where lead paint is being sanded, the operator must wear a protective respirator, as should others working in the same area, and such work should only be done in vacant dwelling units.

After scraping or sanding, all scrapings and dust should be collected by sweeping and/or vacuuming and placed in a tight container for disposal. 
In some cases it may be necessary to remove wallpaper to get at old leaded paint beneath it. If the wallpaper has not been painted over or it is not a water and grease resistant type, no particular problem should be encountered. Use of a conventional wallpaper steamer with a penetrant in the water should loosen the paper for stripping, even if several 1 ayers are present. Mechanical wallpaper removers are also avail able.

Removal is a great deal more difficult if the wallpaper is of the water-resistant type, or if it has been painted over. If this is the case, the surface should be scored to facilitate penetration by the vapors generated by the wallpaper steamer (scoring is also helpful with ordinary wallpaper that has not been painted over). Scoring may be done with a hand tool or with a rotary power hand tool, as described under "Mechanical Removal." In some cases steaming may be useless and only mechanical removal will be effective.

\subsubsection{Matrix II: Surface Repair Methods}

(See Figure IV.)

\section{Definitions}

A. Patch - Repairs made to walls or ceilings that contain voids or deteriorated areas 1 ess then 16 inches in diameter and that comprise less than $20 \%$ of the total affected area are considered as patches. Sufficient backing material (wood, metal or plaster lath) must be present to allow direct application of patching material. Patches also may include minor work on woodwork, etc. 
B. Major Repair - Major repairs include those made to walls or ceilings

1) that contain voids or deteriorated areas greater than 16 inches in diameter; or

2) where some of the backing material (wood, metal, plaster 1 ath) has been destroyed and must be replaced prior to application of patching plaster; and

3) where patch areas comprise more than $20 \%$ of the total affected area and the combination of patch areas and other areas in need of repair is less than $50 \%$ of the component area.

It also may include repair of woodwork, etc.

C. Replace - When more than $50 \%$ of a surface (i.e., a single wall or ceiling) is in need of major repair, the component should be replaced. 3.3.4. Matrix III: Cover Up - Unfinished Membrane Material (See Figure V.)

\section{Definitions}

A. Fabric - Heavy duty fabrics, such as canvas or glass cloth, that may be attached by means of suitable adhesives. (These products can be obtained either unfinished or coated with a decorative finish.)

B. $\quad$ Plaster - A paste-type material composed of gypsum, lime, and water that hardens on drying. (Plaster can be applied in three ways: 1) to lath directly, attached to existing walls, 2) to 1 ath after existing plaster has been removed and 3) as a veneer coating over existing wall surfaces without the use of lath. The first two application procedures are discussed in this section; additional information on these methods 


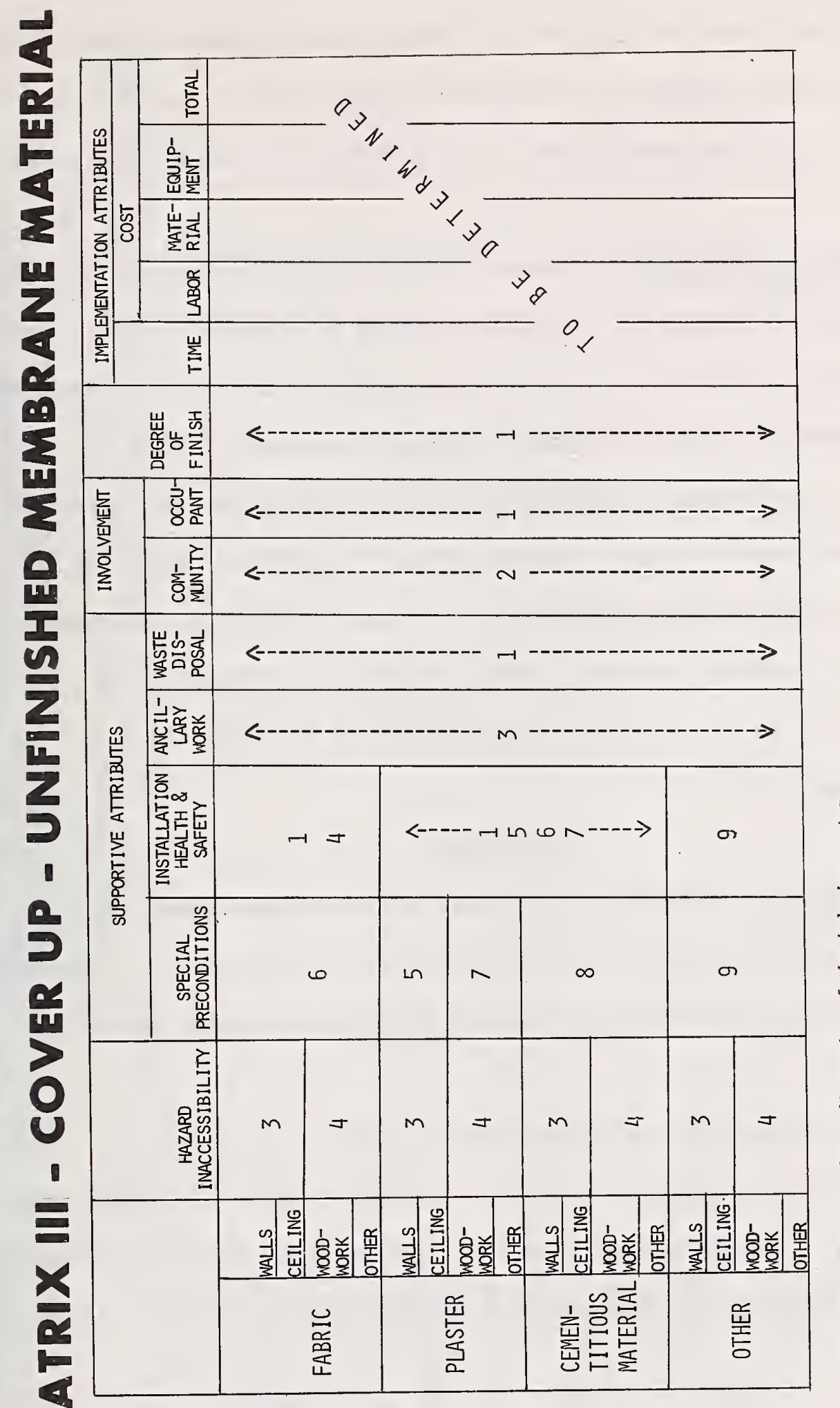

$>$
0
2
7
0
$\substack{-1 \\ \text { I. }}$

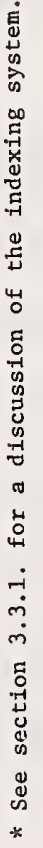


is given in the previous discussion of Matrix II - Surface Repair Methods. The use of veneer plaster as a finish coat for dry wall installations is treated in the analysis of Matrix VI - Surface Finish Methods, that follows.)

C. Cementitious Material - A water slurry of portland cement plus additives that may be applied as a veneer coating by brush or trowel. (This slurry may be reinforced with fibrous materials to improve its physical properties such as tensile strength, impact resistance, etc.)

D. Other - Any material applied in paste or film form, reinforced or nonreinforced, that does not contain gypsum or portland cement as a base. Materials of this kind include the many plastic formulations that could be applied by spray, brush, roller, or trowel.)

3.3.5. Matrix IV: Cover Up-Unfinished Rigid Material (See Pigure VI.)

Definitions

A. Gypsum Board - A board product available in large sheets that usually consists of several plies of paper or felt bonded to a hardened gypsum plaster core. (Special moisture resistant products can be obtained.)

B. Plywood - A structural board product consisting of sheets of wood glued together with the grains of adjacent layers placed at right angles to each other. (Interior grade products bonded with exterior grade glues are available for use in applications where moisture is likely to occur.) 


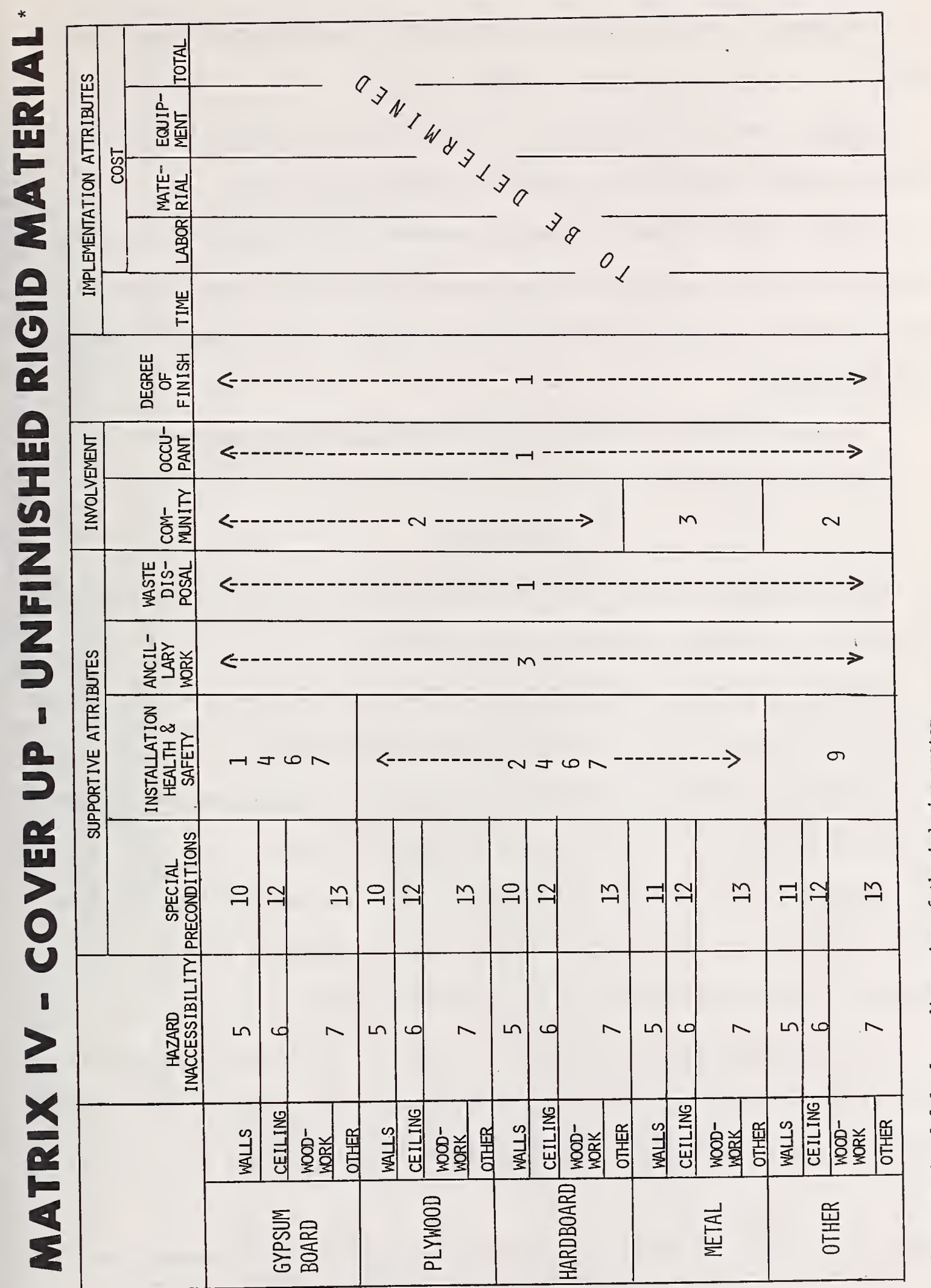


C. Hardboard - A composition board made by compressing shredded wood chips and a binder at elevated temperatures.

D. Metal - Panels of aluminum or steel that can either be installed in proprietary systems or attached by conventional means.

E. Other - This category includes asbestos cement board, glass fiber reinforced plastic panels, and boards made from any of the composite materials that are on the market, e.g., plastic foam or paper honeycomb core materials.

3.3.6. Matrix V: Cover Up - Prefinished Rigid Material* (See Figure VII.)

\section{Definitions}

A. Gypsum Board - Gypsum sheet, supplied with a factory applied decorative paper or plastic membrane on one surface.

B. Plywood - Factory supplied wood 1 aminates with a decorative surface of paint, plastic film, paper, or finished wood veneer.

C. Hardboard - Factory supplied wood particle composition board with

a decorative surface of paint, plastic film, or paper.

D. Metal - Factory predecorated panels of aluminum or steel finished with either paint or a plastic film. (Installations of this kind of material are generally done on a custom fabrication basis.)

E. Reinforced Plastic - Plastic resin panels reinforced with glass fibers usually supplied with a decorative gel-coat finish. (The panels may be finished with paint or a plastic film if desired.)

* Recommended installation procedures, developed by the manufacturers of the various products discussed in this section, should be used. 


\begin{tabular}{|l|r|r|r|r|}
\hline & & & \\
\hline
\end{tabular}

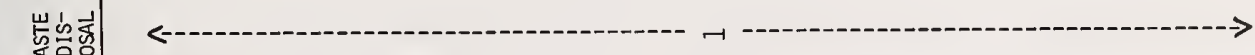

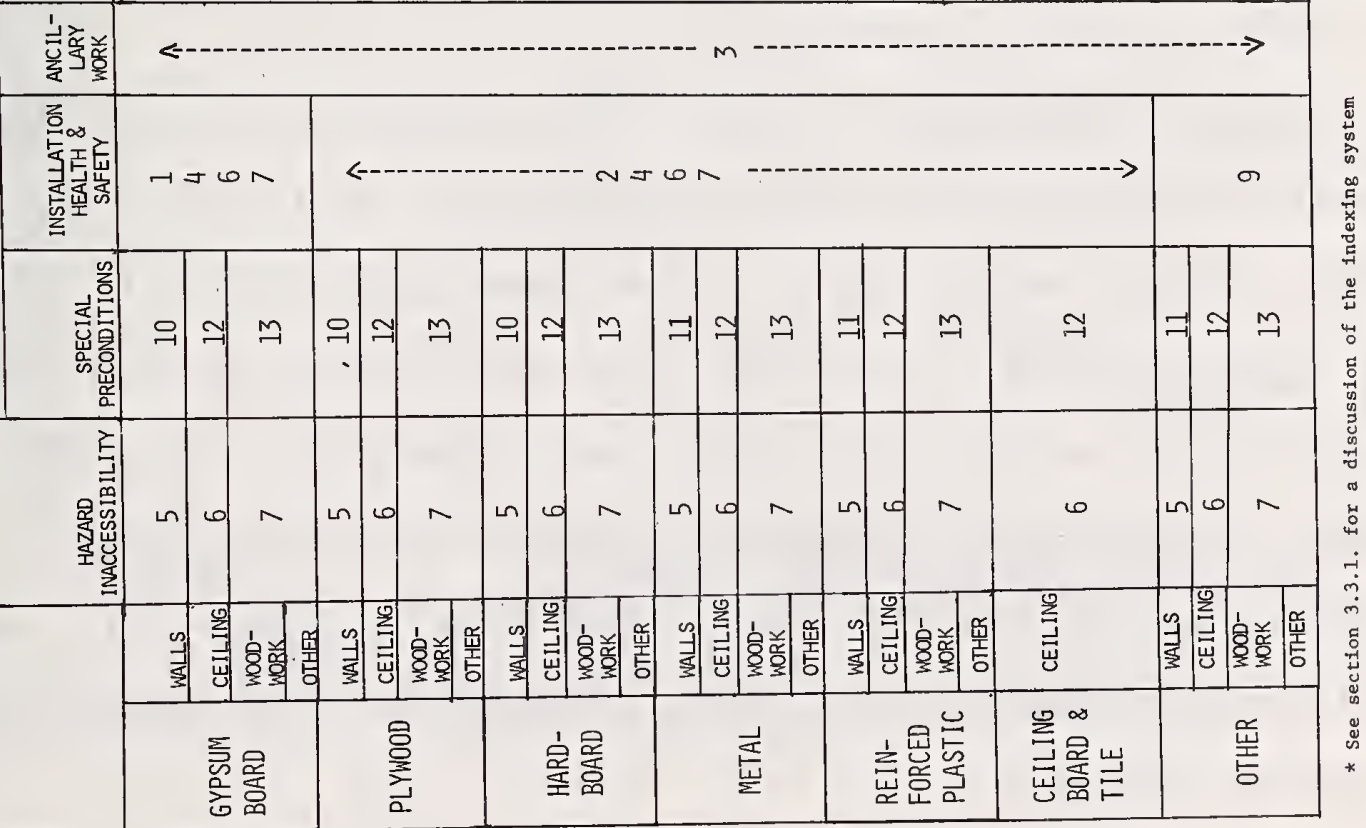


F. Ceiling Board and Tile - These products may be produced from vegetable fibers, mineral wool, glass fibers, metal, plastic, hardboard, or similar materials. (Porous non-bridging paints and plastic films are generally used as surface finishes. Tile can be attached directly to the ceiling. Panels are usually used in combination with proprietary ceiling panel suspension systems.)

G. Other - This category includes any of the composite materials that are on the market, e.g., foam or paper honeycomb core materials sandwiched between plastic films.

\subsubsection{Matrix VI: Surface Finish Methods}

(See Figure VIII.)

\section{Definitions}

A. Paint - A liquid mixture of pigments and a vehicle, either organic or aqueous, that dries to form a cohesive and adherent coating when applied to a surface as a thin film. (It is generally applied by means of a brush, roller, or spray gun.)

B. Masonry Conditioner - A product that penetrates and bonds chalked, painted surfaces to the substrate beneath them. (It is frequently formulated with tung oil-based or other penetrating vehicles.)

C. Liquid Covering - Any of the plastic-based liquid paint-type coatings available on the market, e.g., epoxy, polyurethane, and vinyl. (These coverings may be mixtures of more than one component, and are generally more durable than commonly used 1 atex or alkyd paints. Special application equipment may be required; manufacturer's recommendations should be followed.) 
D. Vinyl Sheet - Flexible vinyl material, available in either sheets or rolls, that is usually laminated to walls with adhesives. (It can be used to provide both a protective and a decorative finish.)

E. Wallpaper - Paper-based coverings that can be used as a decorative and protective finish. (They are usually applied with water soluble adhesives and are not recommended for use where exposure to moisture is 1 ikely.)

F. Fabric - Heavy-duty woven materials usually plastic-based, that may be prefinished with a decorative and protective coating. (Fabrics are generally applied with adhesives.)

G. Plaster and Cementitious Material - Paste-type materials, based on either gypsum or portland cement, that can be applied wet as a veneer to provide a hard surface finish on drying. (These materials may be available pigmented. They are not recommended for use where exposure to moisture is likely unless an additional protective finish is provided.) H. Other - Any finish material other than those previously described, that is applied in paste or film form, reinforced or non-reinforced, and that does not contain gypsum or portland cement as a base. (Materials of this kind include many of the reinforced industrial facings that may be applied with adhesives.) 


\section{Materials Selector Guide}

The Materials Selector Guide in table 2 presents attributes of typical materials that are presently available for hazard elimination. Both membrane-type and rigid materials are 1 isted.

The membrane category includes those materials that are flexible and can be applied to existing or repaired substrates in 1 iquid or paste form, or applied as films or fabries with an adhesive. The rigid classification includes materials that possess some degree of inherent structural rigidity such as gypsum board, plywood and hardboard. Rigid materials may be mechanically fastened or applied to existing substrates with adhesives; they can also be directly attached to structural elements.

The material elements listed represent general categories and the attributes given include a range of values that are typical of the above materials. Comparisons between different materials in the same category should be made on the same basis, e.g., a semigloss alkyd should be compared with a semigloss epoxy.

The attribute classifications given in the Materials Selector Guide were chosen to provide the user with basic information about the applicability of materials to solve the lead paint problem. Surface applicability conditions are covered in column 1 , column 2 outlines the hazard elimination effectiveness, while columns 3, 4, and 5 are concerned with installation costs. The cost figures given do not include surface preparation (furring, paint removal, etc.) or ancillary work (plumbing, electrical, etc.) since these costs can vary widely among housing units. 
TABLE 2

MATERIALS SELECTOR GUIDE

for

Covering Leaded Paints on Walls and Ceilings

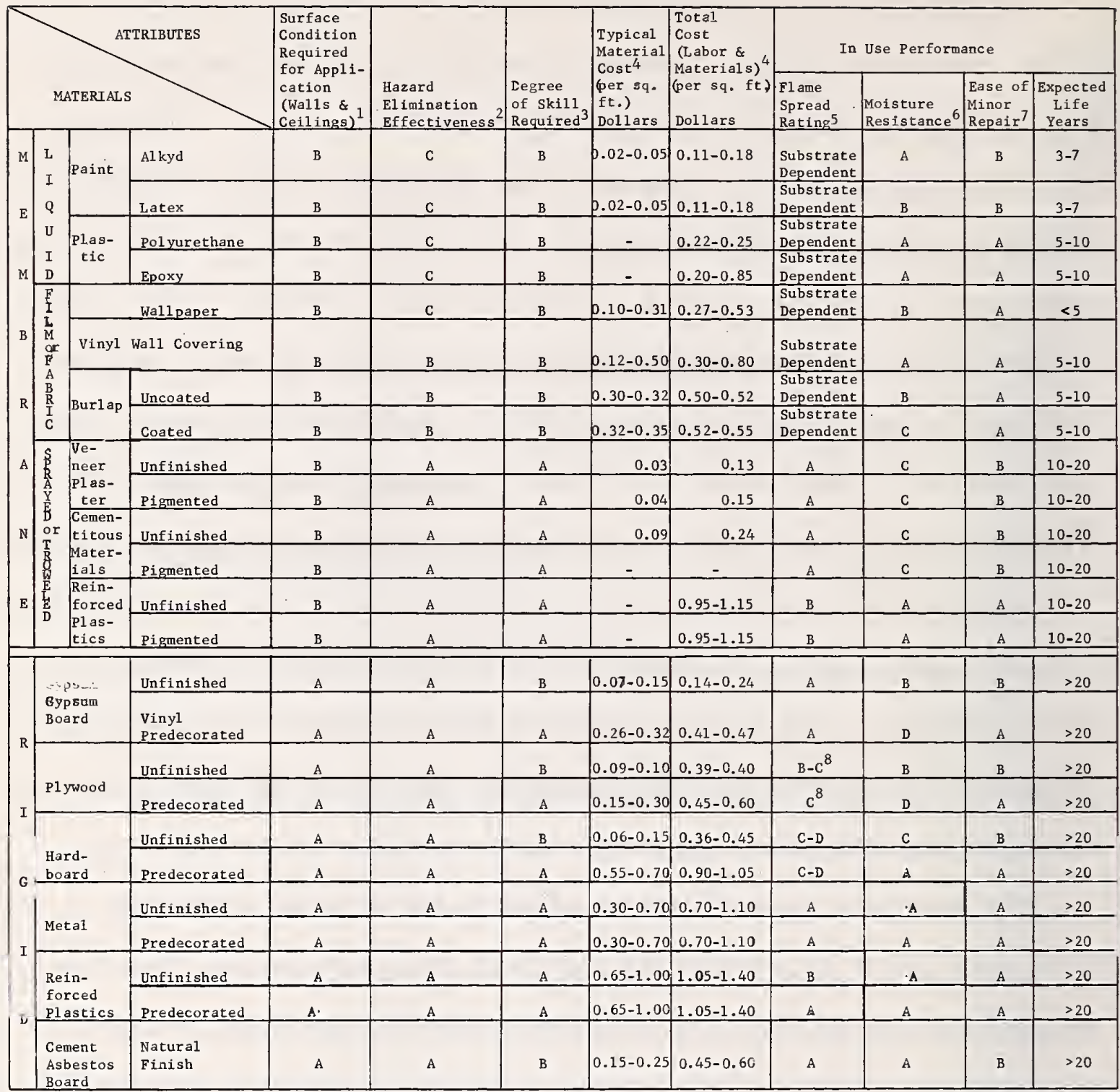

1. A - On all substrates in any condition.

B - On substrates in good repair.

2. A - Effective in all areas.

$B$ - Effective outside reach of children.

C - Does not provide an effective barrier.

3. A - Skilled 1 abor required.

$B$ - Suitable for trainees under skilled supervision.

4. "Building Construction Cost Data," Robert Snow Means Company, Inc., Duxbury, Mass. 02332, 30th Ed., 1972

5. A - 0-25 Flame Spread Rating (ASTM E-84)

B - 26-75 Flame Spread Rating (ASTM E-84)

C - 76-200 Flame Spread Rating (ASTM E-84)

D - Over 200 Flame Spread Rating (ASIM E-84)
6. A - Naturally moisture resistant, suitable in wet areas. B - Special moisture resistant grades available.

C - Requires additional moisture resistant coating.

D - Not recommended in wet areas.

7. A - Skilled labor required.

B - Easily repairable.

8. Special products with increased flame spread rating available. 
The attributes listed in columns $6,7,8$, and 9 deal with the inuse performance of the materials. Flame spread potential, moisture resistance, minor repair potential, and expected life were considered under this classification.

\section{Summary of Hazard Elimination Procedures}

\subsection{Preliminary Conśtderations}

There are three basic ways to prevent the exposure of children to leaded materials in housing:

1. not permitting children in housing where leaded paint is present,

2. covering up the leaded material, and

3. removing the leaded material.

If the first approach is used, and the leaded material is not removed, it would be necessary to ensure that children do not move into the dwelling at a later date since the hazard would still be present. This approach would most likely require the relocation of a large number of families with children.

Covering up the leaded material with an effective barrier layer is a reasonable approach to eliminating the problem. All potentially accessible leaded surfaces should be covered up to make a residence completely free of the hazard. If they are to provide a satisfactory barrier to the leaded materials beneath them, the covering materials used should be capable of withstanding the abuses that they will be subjected to by the occupants of a dwelling unit.

Removal of leaded materials is also a satisfactory solution to the problem. Only complete removal of all potentially accessible leaded materials will totally eliminate the hazard. 
Other approaches that have been suggested include the use of chelating paints, bad tasting paints, and emetic paints. The effectiveness of these coatings has not yet been determined, so that they are not recommended at this time. Making parents aware of the problem and instructing them to keep their children from chewing leaded materials is another approach that may offer some potential for dealing with the problem.

At the present time, the only proven procedures that are available for eliminating the hazard are either removal of the hazard, or covering it up with a suitable barrier. The choice between removal and cover up procedures will be determined by economic factors and the degree of rehabilitation that is desired. For example, if a wall surface is badly deteriorated, covering up may be much more desirable since it will provide a new surface.

Since a child standing on a chair or bunk bed can reach up to the ceiling, only complete removal or covering up of the hazardous material will make it totally inaccessible to children. When financial considerations make it impractical to completely eliminate the hazard in all housing containing leaded paint, trade-offs in the extent of hazard elimination will have to be made.

\subsection{Hazard Potential}

All leaded material in a child's environment represents a potential hazard. The allocation of funds to eliminate the hazard should be based on the accessibility of the hazard. Accessibility conditions that are representative of the immediacy of the hazard to children are: 
1. loose leaded material 1ying on the floor,

2. blistering and peeling leaded paints;

3. readily removed, poorly bonded, leaded paint, and sealants (including putty and caulking compounds),

4. tightly adhered leaded material on surfaces with chewable configurations, within the reach of children,

5. tightly adhered leaded material within the reach of children that can be loosened from nonchewable surfaces by certain actions, e.g., by scratching or banging,

6. tightly adhered leaded material outside the reach of children in locations where conditions in the residence can cause deterioration of the surface; e.g., by moisture in kitchens and bathrooms or by heat in kitchens or around radiators, pipes and ducts, and

7. all other tightly adhered leaded material outside the reach of children.

Since leaded materials in conditions one to four are immediately accessible to children, top priority should be given to these situations. The next highest priority should be given to materials in condition five, with consideration given to materials in conditions six and seven if funds are available. 


\section{A. Removal}

Both sanding and scraping are currently being used to remove leaded paints. Paint removers and heat softening are commonly used to loosen tightly adhered paint before it is removed by scraping.

To date, the use of removal methods has generally been limited to doors, windows, wood trim, and similar items because of problems associated with them. For example, sanding creates considerable amounts of leaded dust, the use of an open flame to soften paints gives rise to a potential fire hazard, and many of the paint removers currently available are toxic and/or flammable. Two approaches that have met with some degree of success in the removal of well adhered paints in occupied housing are the use of electrically heated paint scrapers and the use of high intensity heat 1 amps to soften the paint prior to scraping. They do not give rise to the hazards that were previously mentioned.

Removal methods are not commonly used on plaster walls because of their tendency to damage the walls and because of the hazards created in the removal process. If paint is removed from a deteriorated surface, the surface will still be deteriorated after the work is completed. It is generally more cost effective to cover up leaded paints if more than a minimal job of hazard elimination is to be carried out. (A minimal job is defined by conditions one to four of section 5.2.)

* More detailed discussions of the properties of currently available removal and cover up systems are given in Appendix A. These discussions are indexed by means of the matrices given in section 3.3 . 


\section{B. Replacement}

In many cases it is more desirable to replace components such as doors, windows and wood trim than it is to cover up or remove leaded paints that are on these components. It is a common practice in many cities to replace these items especially when the costs of replacement are comparable to those of the other procedures. In addition, these components are frequently in such disrepair that they merit replacement. Since the replacement of lead bearing components does not expose the residents of a dwelling to the hazards that are created when most removal procedures are used on a large scale, they do not require the costly relocation of families that may be required with removal methods.

\section{Cover UP}

The term "covering materials" encompasses a wide variety of materials ranging from rigid panels such as gypsum board, plywood and hardboard to 1 iquid paint-type coatings such as 1 atex, urethane and epoxy. They can be applied over existing surfaces by means of mechanical fasteners, adhesives, or a combination of the two, or they may be selfadhering as is the case with coatings such as paints. Rigid panel systems in which the covering materials are attached to existing structural components by means of mechanical fasteners are most desirable from a hazard elimination viewpoint. Adequate performance of systems that are installed with adhesives and self-adhering systems that are used to cover up leaded paint is dependent on the condition of the paint and plaster or wood beneath them. 
If the leaded paint, or the substrate to which it is applied, becomes loose the protective covering adhered to it will be adversely affected. With some coverings such as burlap that have a certain degree of intrinsic strength, localized delamination will not cause the exposure of leaded paints. In the case of other coverings such as latex or alkyd paints that do not have much strength, the lead hazard will reappear if localized delamination occurs.

Specific covering materials that are available for use as a barrier to leaded paints are discussed below.*

1. In cases where considerable surface deterioration is present, rigid covering materials, such as gypsum board, plywood and hardboard are probably the most desirable commonly accepted building materials that can be used.** The use of adhesives to attach rigid materials without mechanical fastening is somewhat less desirable since the bond strength is only as good as the strength of the substrate that the adhesive is applied on. Since board materials are both strong and rigid they can maintain their effectiveness as a barrier layer even if there is localized separation from the surfaces to which they are attached. When these materials are used to cover up surfaces that are badly deteriorated, the board thicknesses and support spac-

* The rankings used are tentative, and subject to change as more information becomes available.

** When these materials are applied with mechanical fasteners or a combination of mechanical fasteners and adhesives, and the structural elements covered by them are capable of providing support. 
ings recommended by the respective manufacturers for installation on studs or furring strips should be followed. If the surfaces are in relatively good condition, and are capable of providing substantial support, thinner materials can be attached directly to them.

2. Next in order or desirability* are heavy duty wall coverings such as canvas, glass cloth, vinyl sheeting and similar materials that have faitly good strength. In general, these systems are applied with adhesives and are only applicable to covering up surfaces that are not in a deteriorated condition. If these coverings become delaminated in localized areas from the surfaces to which they are attached, they will probably continue to perform effectively as a barrier, especially in areas outside the reach of children. Since this separation can telegraph through the covering material there is frequently an appearance problem when delamination occurs.

3. Veneer plaster, veneers of other cementitious materials (e.g., coatings composed of sand, portland cement and resin that are sprayed on concrete work), high build textured paints and similar materials would fall into the next category. They will. probably perform adequately as a barrier to leaded materials as long as they remain adhered to the substrate beneath them.

* In many cases, the degree of deterioration cost factors and the amount of weight that walls and cellings can support may make these materials more desirable than rigid boards even though patching may be required before these coverings can be applied. 
These materials generally have low strength, as compared to the previously mentioned systems and will crack and chip if they become delaminated from the surface to which they are applied. If this occurs, they will no longer be effective as barriers to the leaded paint.

4. Ordinary interior house paints such as those of the latex and alkyd-based varieties are not very effective as barriers to leaded paint. They are not as resistant to damage as the previously mentioned covering materials, and since they have relatively poor tear resistance they will not perform as a barrier layer if the leaded paint beneath them becomes loose. Their primary uses in the hazard elimination process are'to provide a readily applied although possibly temporary barrier and to provide a decorative and protective coating on unfinished materials used as a barrier to leaded paints.

\subsection{Properties of Hazard Elimination Systems}

When sufficient funds are available, the permanence of the hazard elimination should be given top consideration when deciding among alternative methods. For example, if only loosely adhered leaded paint is to be removed, the degree of adhesion of the leaded paint in the dwelling must be determined, as must the integrity of the plaster, woodwork and other substrates to which it is applied. If covering materials are to be used, their tear strength and impact, aging, scratch and gouge resistance should be considered. Adhesion and moisture resistance are 
also important where they are applicable. Of equal importance are properties related to health and safety such as flame spread, smoke development, and toxicity. Vermin resistance and mold growth resistance should also be considered.

Cost factors are another important consideration. In addition to costs of materials and labor, the costs of relocation should be considered when methods are used that cannot be carried out in occupied dwellings. Since many hazard elimination methods require considerable labor the suitability of a method for use by "self help" labor can be an important cost consideration.

Properties that affect the aesthetic qualities of a dwelling, such as colorfastness, washability, dirt collection resistance, maintainability, color and reflectance, acoustic properties, attachment capability and appearance are also important.

All of the above properties are discussed in detail in Appendix A of this publication.

Currently available hazard elimination procedures have been summarized in this publication. The choice among them should be based on the conditions encountered in housing and the needs and resources of the community. 


\section{References}

[1] Testimony of M. K. Duval, Hearings on S.3080, Amendment to Lead Based Paint Poisoning Prevention Act, Subcommittee on Health, of the Committee on Labor and Public Welfare, U.S. Senate, NinetySecond Congress, Second Session, March 10, 1972.

[2] Lin Fu, J. S., "Lead Poisoning in Children," U.S. Department of Health, Education and Welfare, Public Health Service Publication Z108, 1970, p. 11 .

[3] Chisolm, J. J., "Treatment of Lead Poisoning," Modern Treatmert, Vol. 4, July 1967, pp. 725-726.

[4] Personal Communication with Samuel Toner of Product Evaluation Division, National Bureau of Standards.

[5] Personal Communication with Gerhard Brauer of the Dental Research Section, Polymers Division, National Bureau of Standards.

[6] Paints and Protective Coatings, Army TM5-618, Section 4.4.3.6, p. 4-17, Superintendent of Documents, Washington, D.C., (1969). 
Appendix A

Hazard Elimination Considerations*

\section{A.1. Hazard Inaccessibility}

1. Access by children to leaded paint on walls, ceilings and woodivork is dependent on the degree of removal carried out. If only loose paint is removed, children can gain access to leaded paint by chewing tightly adhered paint on accessible surfaces or by loosening paint within their reach by physical means such as kicking or banging. Natural causes, such as moisture, can cause presently inaccessible leadedpaint to become an accessible hazard at a future date.

Other surfaces such as exposed pipes, radiators, and furniture should be considered in the above manner.

Removal and replacement of woodwork will attain the same goals as removal of paint from the woodwork.

It should be remembered that only complete removal of all leaded material totally eliminates the potential for recurrence of the problem.

2. Surface repair procedures help to control the hazard accessibility by reducing possible further deterioration of surfaces such as walls and ceilings that are coated with leaded paint. If repair or replacement is of less than $100 \%$ of the total area, the hazard remains. Access to the remaining leaded paint can be gained by chewing tight paint on chewable

* The discussions given in this Appendix are identified by means of numbers that are indexed in the matrices given in section 3.3 of this publication. They are intended for use in conjunction with said matrices. 
(Hazard Inaccessibility, 2 continued)

surfaces, loosening of tight paint by means of the activities of a child, or loosening of tight paint by natural causes, e.g., moisture. No matter how tight the bond may seem between substrate and leaded paint, the leaded material is still present and potentially dangerous. Patching or repairing deteriorated surfaces merely helps to reduce hazard accessibility in the area treated. Only complete removal of all leaded material guarantees total elimination of the hazard.

3. Fabrics and other flexible membrane-type materials are almost always laminated to walls and ceilings with adhesives. These materials should be applied over tightly adhered paint only after loose paint and plaster have been removed and large holes patched.

When plaster is applied on 1 ath, as discussed in Special Preconditions, item no. 2, there would be 1 ittle potential for recurrence of the lead hazard.

Cementitious material can be applied over tightly adhered paint after loose paint and plaster have been removed. Surface preparation to provide good adhesion is essential; bonding agents may be used.

If plaster is used as a veneer over tightly adhered paint, the comments written above for cementitious material are applicable. In general, the bond of plaster to paint will not be adequate unless prior surface preparation is undertaken.

The above two procedures have been used with apparent success, however, limited information about their performance over a period of time is available. 
(Hazard Inaccessibility, 3 continued)

The above cover up procedures are not recommended for use in areas within reach of a child since it would be relatively easy for him to gain access to the hazardous material by tearing or chipping the covering material from the surface.

In areas above the normal reach of children, these cover up methods would be satisfactory, although there is still a possibility of delamination due to natural causes, e.g., moisture. This would result in subsequent failure of the covering material.

4. Fabric cover up of woodwork and other surfaces may be possible in very 1 imited cases, but only as a temporary measure. In areas within reach of a child, where it would be relatively easy to remove the fabric from the woodwork, this type of application is not desirable.

Cover up of woodwork with plaster or cementitious material is possible but not practical since woodwork is generally subjected to a considerable amount of abuse. The resistance of these materials to impact forces is rather low and, therefore, they are not considered to be adequate for permanent hazard elimination. These materials in general would not be adequate for other surfaces.

5. Under normal usage conditions, rigid materials are satisfactory for eliminating the hazard. Hazardous material is made inaccessible only where it has been covered with a suitable material. If a wall is only partially covered and leaded material is left exposed, no matter how 
(Hazard Inaccessibility, 5 contirued)

well adhered the leaded paints are above the covered portion, the potential of accessibility by peeling, flaking, or activities of the child is ever present. Partial coverage of walls is successful only if it extends beyond the maximum reach of the child. A child 45 inches tall (average 6 years old) standing on a 50 inch high bunk bed can reach over 8 feet. The 50 inch bunk bed would probably provide the greatest height access to the hazard. Tables, chairs, sofas, high chairs, and base cabinets would all give access over 4 feet. (See Table I.)

Toys, tocls, furniture, or other mechanical means can be used to destroy the covering material, resulting in reexposure of the leaded paint. Resistance to this type of damage is determined by impact resistance, which is a measure of the ability of a material to withstand damage by a striking force, and is a function of the thickness and elasticity of a material. Thus, for a particular type of material, a $1 / 4$ inch thick product is more susceptible to damage than one which is $3 / 8$ inch or $1 / 2$ inch thick.

Very little information is available about the forces that can be generated by children in the age group under consideration. This does not imply that only children will destroy the covering material.

6. Under normal usage conditions, cover up methods for ceilings with rigid materials would provide the maximum possible inaccessibility of hazardous materials. Since the leaded material is still present, however, there is still a very slight potential for recurrence of the prob1 em. 
(Hazard Inaccessibility, 6 continued)

Boards or tiles may be attached directly to the ceiling or ceiling panel suspension systems may be used. The panels in ceiling suspension systems may be removable and consequently the hazard is potentially more accessible than in those systems where rigid materials are fastened directly to the ceiling.

7. When it is possible to use the existing wood trim for attachment purposes, plywood, hardboard, and gypsum board coverings can be applied to window and door trim, baseboards, wainscoting, and in 1 imited instances to stairway balustrades. In most cases windowsills and window sashes cannot be covered by any of these materials. Plywood and hardboard can be used to cover doors and cabinetry (excluding leading edges); gypsum board is not suitable.

Metal is a material that is difficult to use for covering woodwork and its only practical use is on doors.

Reinforced plastics are not appropriate covering materials for woodwork since difficulties would be encountered in attaching plastic panels. Maximum hazard inaccessibility would be provided by metal, plastic, hardboard, gypsum board, and plywood where they can be used, assuming normal usage by the occupants rather than malicious destruction that would allow the hazard to become accessible.

Similar considerations are applicable for other surfaces. 
(Hazard Inaccessibility, 8)

8. Surface finish methods can serve two purposes in the hazard elimination process:

a. As protective and decorative coatings to prevent the deterioration of unfinished covering materials used to prevent access to leaded paints. This additional finish coating is necessary to prevent attack by environmental conditions that would give rise to the degradation of the barrier material and possible recurrence of the hazard.

b. As protective coatings applied directly over tightly adhered leaded paint to protect it from exposure to moisture, and other environmental causes of deterioration.

Surface finishes do not serve as the primary barrier against access to leaded paint when they are used in combination with unfinished covering materials. Hazard inaccessibility for these cases is discussed in conjunction with items $3,4,5,6$ and 7 which deal with unfinished membrane and unfinished rigid materials.

Paint, and other 1 iquid coverings have limited resistance to the damage caused by children, hence they are only appropriate for use on ceilings and wall areas beyond the reach of children.

Flexible membranés such as vinyl sheet, wallpaper, and fabric are laminated to walls and ceilings with adhesives. When the substrate is sound, these materials are satisfactory for use on ceilings and wall areas above the reach of children. They are more durable than paints 
(Hazard Inaccessibility, 8 continued)

and tend to offer more protection against the recurrence of the hazard than do paint coatings. Nevertheless, they are also easily damaged by children.

Plaster and cementitious-type materials have been used with some degree of success as a veneer over a substrate to which paint is tightly adhered. In general, however, since these materials require a porous substrate for good adhesion, their suitability for use over a painted surface is questionable, but may be enhanced by the use of surface roughening agents or bonding agents prior to application. These veneers do not provide a very effective barrier in areas that can be reached by children because they can be easily chipped and damaged.

Other materials that may be used include the various resin bonded fiber-reinforced composite materials that are currently available. Application methods similar to those for fabrics would probably be used. Subsequent loosening of the tight, leaded paint, to which all of the above coverings would be bonded, could cause the recurrence of exposure to the hazardous materials.

The effectiveness of surface finish techniques as a barrier to leaded paint on woodwork has not yet been demonstrated. It is generally more practical to remove the leaded paint from the woodwork or other surfaces such as exposed pipes. Complete replacement of woodwork may be advantageous.

If surface finish methods are to be used as a barrier over woodwork, materials such as fabric, vinyl sheet, wallpaper and some other products should be chosen rather than paint-like coatings. When subjected to 
(Hazard Inaccessibility, 8 continued)

chewing, impact, or other child related activities, these materials are more likely to maintain their integrity than paint-type coatings. However, once the protective film is ruptured, removal of the material by a child and subsequent reexposure to the hazard can result.

\section{A.2. Special Preconditions}

1. Surfaces from which paint will be removed should be capable of being repaired if necessary. (See item 2.)

Adequate precautions should be taken to protect occupants and workers from hazards created while the work is being carried out. (See Installation Health and Safety.)

Electrical and other fixtures should be protected from damage by chemicals, heat, and dust when necessary. Similar protection should be provided for surfaces that will not be treated.

2. Prior to any patching, the extent of deteriorated areas and voids must be determined. All loose materials must be removed to a point where the remaining material is adequately bonded to the backing system.

Conditions for the support of walls and ceilings require that the basic structural components such as studs and ceiling joists be sound and capable of performing their intended function. The decision concerning the ability of structural components to perform their original function must be based on the judgment of a building inspector or other qualified personnel. 
(Special Preconditions, 2 continued)

Patching procedures may require the application of more than one material. If deterioration or voids extend to the backing system (wood, metal, or plaster 1 ath), then a base "scratch" coat of plaster must be applied first, followed by a "white" coat of finish material. If the base coat is adequate, only a finish coat of plaster or spackling compound need be applied to complete the patch. The smallest areas that would be patched are nail holes or cracks that cannot be covered by the decorative coating to be used on the walls or ceiling.

3. Woodwork patching procedures involve filling small nail holes and cracks with wood putty, or similar products. They also include restoring loose components by nailing and/or gluing. The woodwork involved which may include windows, doors and associated trim, baseboards, kitchen cabinetry and balustrades, must be firmly attached to the structural components of the dwelling.

Major repairs to woodtrork include the replacement of parts of items such as window or door units. Examples would be replacement of a windowsill, one side of a kitchen cabinet, or a balustrade spindle. Preconditions necessitating replacement would be that the existing component be cracked, split, or deteriorated to a point where it can no longer perform its intended function. If a component is simply loose and can be repaired with the use of mechanical fasteners, it would not be considered as a major repair. The item being repaired must have suffjcient integrity to permit the performance of its intended use when a component part is replaced. 
(Special Preconditions, 3 continued)

When a wall is replaced because of voids or deterioration, the trim must be removed. The possibility of reusing woodwork taken from walls in this condition is rather remote. It is usually necessary to replace the window and door trim, baseboards, etc. The replacement of doors, doorjambs, windows, windowsills, kitchen cabinetry, kitchen and bathroom fixtures, or any woodwork depends on the ability of these components to perform their original function. This judgment would have to be macie by experienced personnel.

4. Before major repairs can be initiated on walls or ceilings, the studs and ceiling joists must be determined to be structurally sound and capable of supporting the application of both the new backing material and the plaster patching system. Where voids exist, the addition of new lath may be required to support the patching plaster. The plaster adjacent to the void must be removed to expose at least two studs or ceiling joists capable of supporting the new 1 ath. The patching procedure to be used after the application of new backing material is described in item 2.

The definition of a major repair stipulates that the combination of patch areas and other repair areas must not total more than $50 \%$ of the component area being considered. This percentage is an estimate, and the final decision regarding the process to be used should be based on a cost analysis of both major repair and complete replacement procedures. 
(Special Preconditions, 5)

5. Replacement of the entire wall or ceiling system is usually required when plaster walls and ceilings cannot be economically repaired by patching or major repair procedures.

Exploratory removal of plaster and lath should be carried out to permit visual inspection of structural members and thereby assess their ability to support the new system. If the structural components are found to be adequate, a new plaster system can be installed. If the structural components are partially or totally inadequate, they must be replaced or repaired to supply adequate support prior to application of the new plaster system. If structural components cannot be restored, condemnation of the building should be considered by the appropriate authorities.

The existing wall or ceiling lath systems may require replacement if they are found to be unsound after the plaster is removed. This would involve removal of all lath down to the basic structural members (i.e., studs or ceiling joists). If the existing lath system is found to be in adequate condition, it can be reused.

Removal of window and door trim, baseboards, and/or wainscoting may be required since these items are usually applied to the walls on top of the plaster and lath.

In some cases it may be possible to apply metal lath on top of the existing lath system, but the general rule would be to completely remove all damaged lath. In certain isolated cases it may also be possible to apply new metal lath directly to existing walls or ceilings without removal of the plaster. 
(Special Preconditions, 5 continued)

When a plaster veneer is used to cover up leaded paint on walls and ceilings, an adequate mechanical bond must be provided between the existing systems and the new plaster. This bond can be provided by attaching 1 ath to existing surfaces, as mentioned above, or by using the various bonding agents that are available.

6. The application of vinyl sheet, fabric, and wallpaper requires that all loose material be removed, all surface defects be patched or repaired, and that an adequate bond be provided between the surface and the fabric. Imperfections in the surface must be held to a minimum since they will show through fabric-type materials.

Any holes greater than 1/16 inch in diameter must be patched. High gloss areas should be roughened in order to produce a surface that will allow bonding of the fabric to the substrate. This roughening can be accomplished by sanding or similar surface treatments.

Paint-type primers are not necessary for use on new plaster, although they may be used. New plaster surfaces can be primed or sized less expensively with a diluted adhesive coat that is allowed to dry. A manufactured sizing material may also be applied prior to the application of sheet material with adhesives.

Low permeability, water-resistant coverings and moisture-resistant laminating adhesives should be used in areas where exposure to moisture is likely to occur. Smooth surface configurations, e.g., untextured wainscoting and smooth stairwells, are desirable when vinyl sheet, wallpaper and fabrics are applied. 
(Special Preconditions, 7)

7. The cover up of woodwork by plaster would require the application of a bonding medium to the woodwork prior to plastering. This bonding medium may be either expanded metal 1 ath, plaster 1 ath, or a bonding agent.

8. Supportive requirements for the application of cementitious materials to walls, ceilings, and woodwork are that the surfaces be free of loose or high gloss material; in addition, woodwork must be firmly attached to structural components. Adequate adhesion to the surface can be obtained when suitable bonding agents are used. Mechanical bonding of cementitious materials to surfaces can also be provided by the attachment of supportive 1 ath to surface elements.

9. The application of other unfinished membrane materials would require basically the same supportive preconditions as for fabrics or cementitious materials. However, the degree to which the existing systems must be patched may not be as extensive as for fabric, depending on the texture of these materials. The substrate surface must be free of loose material, large voids, and/or glossy surfaces so that a satisfactory bond can be realized.

10. Three application methods for rigid materials can be used; direct attachment to existing walls, attachment to furring, and attachment to framing members. In all three cases the materials to be attached are either mechanically fastened or applied with a combination of adhesives and mechanical fasteners. 
(Special Preconditions, 10 continued)

For the direct attachment method, the existing walls should not be buckled, bulged, or contain large voids. If this condition is met, mechanical fastening $c$ an be used with no further preparation required. When a combination of adhesives and mechanical fasteners is to be used, the walls must in addition be free of dirt, loose plaster, and/or loose paint and be adequately prepared for the use of adhesives.

When the above conditions are not met but the structural components are sound, furring can be used to support the surfacing material. It would be advisable to use furring strips in combination with sound and adequately attached baseboards and window and door trim to support the wall covering. Furring strips should be selected so that they provide a surface in the same $\mathrm{plane}$ as the existing trim. When the existing trim does not meet these conditions, it must be removed and the entire wall surface furred. The surfacing material can then be applied to the furring by either of the techniques described above.

When the existing structural components (wall or ceiling assembly) are not sound enough to permit the use of furring, reframing is necessary. This method provides a structural framework for the attachment of finish materials. Existing exterior walls, and floor and ceiling joists must be solid enough to permit the attachment of the new structural framework. The surfacing material can then be attached to the reframed walls by either of the two prescribed methods. 
(Special Preconditions, 11)

11. Support systems recommended for the type of panel selected should be installed.

In general, since support systems will be fastened to structural members, they must have sufficient integrity to permit attachment of the supportive framework.

When exterior walls are judged to be unsafe, the structure may require condemnation. Inadequate floor or ceiling joists can be repaired or replaced, if this is economically feasible.

12. Support requirements for ceiling installations are similar to those for wall installations. The three techniques used are: direct attachment, furred attachment, and the use of suspended ceiling systems.

For direct attachment of gypsum board, plywood, hardboard, or ceiling tile, the existing ceiling surface should not be buckled, bulged, nor contain 1 arge voids when mechanical fastening is to be used. When a combination of adhesives and mechanical fasteners is to be used, the ceiling surface must in addition be free of dirt, loose plaster, and/or paint and should otherwise be adequate for the use of adhesives. When engineering judgment concludes that the surface is unsuitable for direct attachment, a furring system or a suspended system should be used. Ceiling conditions must be structurally adequate for attachment of the system when furred or suspended ceiling panels are used.

In the case of metal panels the suspended ceiling conditions must be met since there is no direct attachment ceiling panel available. 
(Special Preconditions, 13)

13. The use of rigid materials to cover woodwork or other surfaces is not feasible in many cases. It must be determined that the elements to be covered will be capable of performing their original function after covering. In addition, the woodwork should be firmly attached to the substrate prior to covering.

Gypsum board, plywood, and hardboard can be used to cover window and door trim, baseboards, wainscoting, and balustrades as outlined in item 10. Although gypsum board is not practical for use on doors and cabinetry, thin veneers of plywood and hardboard can be used for this purpose.

Covering up woodwork with metal would be a custom installation for each situation encountered. The practical use of metal would be for covering doors. If metal is used, the requirements would be the same as for the gypsum, plywood, and hardboard; i.e., those elements to be covered must be capable of performing their original function after covering. Reinforced plastic may be used, but is not recommended unless special attachment procedures or techniques are developed.

14. The use of paint-type coverings for finishing surfaces requires that:

a. The substrate be solid and rigid. All weak areas should be removed and repaired.

b. Any old paint which is not firmly attached to the substrate be removed. 
(Special Preconditions, 14 continued)

The satisfactory adhesion of paint-type coverings requires a certain degree of bonding to the existing surface. Areas that are coated with a high gloss paint, e.g., enamel, should either be primed or roughened so that an adequate bond will result. Surface roughening of high gloss areas car be accomplished by sanding or by the use of surface conditioners that achieve the same result. In addition, all surfaces should be free of dust, dirt, and grease. Areas that have been patched with plaster or spackling compounds should be primed and sealed. If these procedures are not followed, the adhesion of the new paint will be reduced.

Some of the aforementioned coatings are apt to contain strong solvents that may cause softening and/or 1 ifting of the old paint. Preliminary test applications should be made to establish whether the old and new coatings are compatible.

In areas where moisture is frequently present (bathrooms and kitchens) low permeability coatings should be used. Solvent-thinned alkyd enamels or 2-component enamels such as the epoxy or polyester types, are advisable. Since flat latex paint is generally more permeable to water vapor than solvent-thinned paint, priming with an alkydbase primer-sealer is recommended. 


\section{A.3. Installation Health and Safety}

1. In addition to removing paint, sanding can also be used to roughen surfaces prior to the application of covering materials.

Considerable amounts of leaded dust can be generated by sanding. Cutting sheet-type materials and removal and application of plaster can also give rise to 1 arge amounts of dust. Since working in closed, unventilated areas presents a health hazard when these procedures are carried out, work should either be done outside the dwelling unit or adequate air flow should be maintained in the work area to remove the dust. Ideally, dust bags should be used with power tools, and respirators and safety glasses should be worn.

2. Care should be exercised to avoid inhaling the minimal amount of dust generated by this method.

3. Burning or softening paint with an open flame within a dwelling causes a fire hazard and may be forbidden by municipal ordinances. Adequate protection should be provided when this method is used.

It is easier to burn and scrape paint from wooden surfaces than from plaster or masonry. This method is not recommended for wallboard substrates or wallpaper.

When high temperatures from paint softening equipment are applied to materials containing lead, some of the lead may vaporize and produce fumes. If controlled-temperature heating devices are used at a temperature below that at which lead vaporizes significantly, this problem will not occur. Adequate ventilation should be provided to prevent trouble from lead fumes. 
(Installation Health and Safety, 4)

4. Water-thinned products usually cause minimal Installation Health and Safety problems. However, when volatile organic solvents are present in paint removers, 1iquid covering materials, liquid surface rougheners, or the adhesives used to apply fabric or membrane materials, hazards can arise. Since most of these solvents are toxic and/or flammable, adequate ventilation should be provided to prevent hazardous fume levels in work areas, and adequate fire protection is essential.

Suitable protective garments, e.g., gloves, should be provided to prevent burns on workers who come in contact with chemical solvents. Municipal regulations may 1 imit or forbid the use of products containing certain hazardous volatile chemicals.

5. Masking tape or some other covering material should be used to prevent the entry of wet materials, dust, paints, adhesives, and/or chemical solvents into electrical outlets and switches. In addition, when wet materials are used, the electrical circuits involved should be disconnected while work is being done.

Equipment used for hazard elimination should not overload the electrical services, or a fire may result.

6. Care should be taken to avoid damaging electrical wiring, gas 1ines, and water pipes with nails or screws.

7. Normal construction site safety precautions should be observed, i.e., the use of hard hats, safety glasses, safety shoes, and work gloves. 
(Installation Health and Safety, 8)

8. Precautions should be taken when heat softening paint near electrical circuitry and gas fixtures.

9. Specific instructions for other materials cannot be determined until those materials are known. The normal precautions taken when preparing leaded surfaces are mandatory. Special precautions that may be required for a specific product should be outlined by the manufacturer. If the manufacturer does not specify particular hazards, an analysis of the system components will reveal whether or not dangerous substances are present.

\section{A.4. Ancillary Work}

1. In general, walls and ceilings require no ancillary work. It may be desirable to remove items such as windowsills, baseboards, doors, windows, etc., to facilitate the removal of paint.

2. Little or no ancillary work on electrical or heating systems is normally needed when patch or major repair procedures are carried out. When wall or ceiling areas are removed because they have been damaged as a result of leakage, repairs to water lines or drain lines may be necessary.

Deterioration of the inner surfaces of external walls may be caused by water leakage through roofs or walls. When a situation of this kind exists, it is usually a violation of housing regulations and appropriate repair procedures should be used. 
(Ancillary Work, 3)

3. Ancillary work connected with replacement or cover up methods may involve electrical, plumbing, and heating distribution systems. They should be performing their intended function satisfactorily when hazard elimination techniques are started. If they are not, a possible code violation exists that should be rectified. Such violations should be recognized as separate problems that are not a part of the lead hazard elimination program. The extent of plumbing and electrical work will depend on each individual case, and cannot be readily estimated without seeing the specific job. When replacement of walls is necessary, it may be in the best interests of the occupants and the owner to replace existing plumbing and electric wiring while it is convenient to do so.

The basic problems encountered depend on the material chosen and the method of attachment. When direct attachment or furred attachment procedures are used, relocation of electrical, plumbing, and heating fixtures is dependent on the total added thickness to the walls and ceilings. When reframing techniques are used, complete renovation of the distribution systems may be necessary.

\section{Ancillary Work (E1 ectrica1)}

Electrical distribution systems may require modifications when substantial increases in wall thickness are made in the course of eliminating the hazard.

When concealed wire installations are present, it is possible to extend existing switch, outlet or distribution boxes using commercially 
(Ancillary Work, 3 continued)

available adapters. Wiring can be lengthened by splicing if it is not long enough to accomodate the added wall thickness.

Conduit-enclosed surface wiring systems can be covered up if the added wall thickness does not exceed the plane of the switch, outlet and/or distribution boxes. Electrical codes generally prohibit the covering up and use of other types of surface mounted systems and they should either be removed and reinstalled on the new surface or disconnected and abandoned.

Ancillary Work (Plumbing)

The possibility of deteriorated plumbing systems is always present; when old systems are disturbed, failures that require costly repairs may occur.

Plumbing problems will occur primarily in bathrooms and kitchens. If at all possible, a hazard elimination method that does not require relocating plumbing fixtures should be used. Sinks, bathtubs, and water closets are generally attached to existing walls. In many cases, fixture movement problems can be eliminated by framing around the fixtures or using thin covering materials that $\mathrm{can}$ be cut to fit around them. Moving a sink simply requires the attachment of longer lengths of pipes to the supply and waste drain lines. Water closet relocations are much more difficult in that the main drain connection establishes the location of the unit. Any relocation would require moving the waste drain line, which would necessitate tearing up the bathroom floor. The possibility 
(Ancillary Work, 3 continued)

of replacing an existing water closet with one of different design that could utilize the existing waste drain may be the economical solution to the problem. Wall areas around bathtubs can be covered without relocation of fixtures if the covering system is not greater than $1 / 2$ inch thick. Shower fixtures and in-wall valves and faucets $c$ an be extended with adapter fittings in most cases.

\section{Ancillary Work. (Heating Systems)}

The types of heating systems that may be encountered are fuel burning space heaters, central distribution-type heating systems, and electrical units.

Fuel burning space heaters include coal stoves, oil stoves, and gas stoves. The oil and gas heaters either use convection or fan driven units to provide air circulation and can be free standing, suspended, or built into the wall. of the fuel burning systems, only suspended heaters and built-in wall units must be dealt with when cover up methods are used. Suspended heater systems may have to be removed during the installation of new coverings; minor alterations to the suspension hangers may be required. Built-in heater units would have to be moved or the trim reset to conform to the established plane of the new wall covering system. Relocation might require adequate framing to structurally support the heater, as well as extension of the piping and exhaust systems. 
(Ancillary Work, 3 continued)

Central distribution systems can use hot water, steam, or forced hot air as a heat transfer medium. Free standing or baseboard type radiators are normally used as distribution outlets for hot water and steam. Forced hot air systems distribute air through either wall-mounted or floor-mounted registers. In the case of hot water or steam radiators, relocation can be accomplished with a minimum amount of piumbing; this would consist of lengthening the pipe lines or using offset adapter couplings. In the case of baseboard systems, it may be necessary to relocate the units to conform to the thickness of the added material. This would require additional lengths of pipe and consideration should be given to structural support and attachment. Forced hot air systems would only require short metal extensions to existing duct work to conform to the new wall system.

Electrical heating systems can use either free standing or wallmounted units for heat distribution. The free standing units do not require relocation, but wall-mounted heaters would have to be relocated and properly supported to conform to the new wall system. If extension of electrical connections is required it should conform to the procedures described under electrical ancillary work.

When working with or around any fuel-dependent or electrical heating devices, extreme care should be exercised in order to prevent the creation of a fire hazard, i.e., fire resistant materials should be used. 4. Any necessary ancillary work should have been performed during implementation of work described by Matrix II, Surface Repair Methods. 


\section{A.5. Waste Disposal}

1. The leaded waste material generated in the removal process is quite hazardous. Care should be exercised to collect and package it to render it inaccessible and disposal should be in a manner that would keep it inaccessible.

Disposal methods that could permit the entry of leaded materials into the environment (i.e., air or water) should not be used.

Removal and disposal should be in accordance with appropriate local ordinances or by recognized safe procedures if pertinent local ordinances do not exist.

2. Non-leaded waste should be removed with care and expediency. Waste material can provide breeding grounds for vermin and thus present a health hazard. In addition, people, especially children, can injure themselves by coming into physical contact with the waste material.

Immediate removal and disposal should be in accordance with appropriate local ordinances.

\section{A.6. Community Involvement}

1. These methods would be well suited for "self help" labor since little or no skill and minimal supervision would be required. (See Installation Health and Safety for precautions that should be taken.)

2. These methods are suited for "self help" labor if the workers are trained and skilled supervision is provided. (See Installation Health and Safety for precautions that should be taken.) 
(Community Involvement, 3)

3. These methods are not suitable for use by "self help" 1 abor because of the high degree of skill required for its implementation.

\section{A.7. Occupant Involvement}

1. The dwelling occupants should be kept out of the immediate area in which work is being done until it is completed and the area cleaned up. (See the Installation Health and Safety section for detailed information about specific hazards involved.)

2. The dwelling occupants should be removed from the residence while the work is being done until it is completed and the area cleaned up. (See the Installation Health and Safety section for detailed information about the specific hazards involved.)

\section{A.8. Degree of Finish}

1. Removal methods, surface repair methods, unfinished membrane methods, and cover up with unfinished rigid materials methods are not normally intended to provide a final finish. These methods generally provide an unattractive, easily soiled, and difficult to clean and maintain surface. Surfaces provided by these methods also are susceptible to moisture attack and degradation by other environmental conditions. Application of a suitable surface finish coating is desirable when these methods are used.

2. When prefinished materials and surface finishing agents are used as intended, they should require no further surface finishing. 
(Degree of Finish, 2 continued)

To ensure adequate service under normal usage conditions, they should meet the requirements recommended for finished materials in Performance (sections A.9, A.10, and A.11). In addition to being decorative, acceptable materials will be easy to clean and maintain, and resistant to moisture.

The texture of the finished surface and properties that are dependent on it, such as ease of cleaning, will vary with the type of material or system used.

\section{A.9. Performance: Health and Safety*}

\section{A.9.1. Fire Resistance}

The materials used should comply with local code requirements that are pertinent to fire resistance.

Building materials used in a dwelling should be capable of containing a fire for a sufficient period of time to permit evacuation of occupants and to allow fire fighters to bring the fire under control.

Materials that have high surface flame spread values and that produce excessive amounts of smoke or toxic gases on burning should not be used in construction or rehabilitation of housing.

* These performance recommendations are intended for use as guidelines when applicable local code requirements are not available. 
(Performance: Heal th and Safety, A.9.1 continued)

In the absence of any local regulations, the requirements of the Federal Housing Administration (FHA) for building material flame spread ratings [1] may be used as a means for judging the suitability of covering materials. FHA requirements for interior finishes in various locations of a building are summarized in table A-1.

\section{A.9.2. Toxicity}

Materials used in housing should be chosen with a concern for the health and safety of the dwelling occupant.

Care should be exercised to avoid the introduction of toxic substances in the course of eliminating the leaded paint hazard.

Finishes that contain toxic compounds as pigments or additives should not be used if the quantities exceed those permitted in American Standard Z66.1-1964 [2] or applicable Federal or local regulations.

\section{A.9.3. Spatial Factors}

All living spaces should contribute to the safety and well being of the occupant.

Ceiling heights, room sizes, lighting, ventilation, and the projection of columns, ducts, plumbing, and similar items should meet the recommendations in the FHA Minimum Property Standards [3].

\section{A.9.4. Vermin Resistance}

Surface elements in a dwelling unit should not be conducive to the harboring or feeding of vermin. Cracks or holes in or between surfaces such as walls, ceilings, woodwork, etc. should be sealed to provide a barrier to the passage of vermin. 
(Performance: Health and Safety, Table A-1)

Table A-1

Flame Spread Rating Limitations of Interior Finishes

\begin{tabular}{|l|c|c|}
\hline $\begin{array}{l}\text { Location Within Building } \\
\text { (1) (2) }\end{array}$ & $\begin{array}{c}\text { Surface Flame } \\
\text { Spread Rating- } \\
\text { Maximum Range (3) }\end{array}$ & $\begin{array}{c}\text { Flame Spread } \\
\text { Classification (4) }\end{array}$ \\
\hline $\begin{array}{l}\text { Enclosed Stairways and Other } \\
\text { Vertical Openings } \\
\begin{array}{l}\text { Corridors or Hallways and } \\
\text { Other Exits (5) }\end{array}\end{array}$ & $0-25$ & Class A \\
$\begin{array}{l}\text { Within Iiving Unit except } \\
\text { for Ritchen Space (6) }\end{array}$ & $0-75$ & Class A, B or C \\
$\begin{array}{l}\text { Kitchen Space Within Jiving } \\
\text { Unit (7) }\end{array}$ & $0-200$ \\
$\begin{array}{l}\text { Public Rooms and Entrance } \\
\text { Spaces }\end{array}$ & $0-75$ & Class A or B \\
$\begin{array}{l}\text { Service Rooms, enclosing Heat } \\
\text { Producing or Other Mechanical } \\
\text { Equipment, and al1 other fire } \\
\text { hazardous areas }\end{array}$ & $0-75$ & Class A or B \\
\hline
\end{tabular}

\section{Notes:}

(1) Windows, doors not greater than $25 \mathrm{sq}$. ft. area, and trim around openings may be excluded in the calculation of flame spread 1imitations for rooms or other spaces. In no case shall the flame spread of doors exceed the acceptable 1 imits for the room where it is used.

(2) Finished floors and floor coverings are not included in flame spread requirements, however where either a floor or floor covering proposed is considered to be a fire hazard by the FHA, it may be required to meet the rating given in this table for the location in which it is used. 
(Performance: Health and Safety, Table A-1 continued)

(3) Any finish material shown by test to have a life hazard greater than that indicated by the flame spread classification due to the amount or character of smoke or toxic gases generated, shall be included in the grouping appropriate to the actual hazard as determined by FHA.

(4) Groupings of Flame Spread Ratings

F1 ame Spread ratings may be grouped into Interior Finish Classes, in accordance with NFPA Standard No. 101, "Life Safety Code," as follows :
a. Class A Interior Finish = Flame Spread, 0-25
b. Class B Interior Finish = F1ame Spread, 25-75
c. Class C Interior Finish = Flame Spread, 75-200

(5) Some conditions require materials having flame spread ratings of not greater than 25 .

Where required, exit stairways are so located that passage through an interior space such as a lobby, corridor, or other similar space is necessary to reach the exterior, the interior space shall be equipped with an approved automatic sprinkler system, unless the construction of the space (floor, walls, ceiling) is 2-hr. noncombustible with Class A interior finish in Types 1, 2 and $3 a$; and 1-hr. rating with Class A interior finish in Types $3 b$ and 4 construction.

(6) For twenty-five (25) percent of the combined wall area of any single room within a living unit, except kitchen space, the finish material may have a flame spread rating up to 225 .

(7) The flame spread rating of kitchen cabinets and counter tops shall not exceed $\mathrm{Class} \mathrm{C}$ or 200. (The recommendations for cabinet location given in the FHA Minimum Property Standards, p. 83, should be followed when cabinets are installed near ranges, cooking units, or other sources of heat.) 
(Performance: Heal th and Safety, A.9.4 continued)

Two tests that can be used to evaluate the vermin resistance of paints, adhesives, etc. are:

a. "Standard Method of Test for Susceptibility of Dry Adhesive Films to Attack by Roaches," (ASTM D 1382) [4], and

b. "Standard Method of Test for Susceptibility of Dry Adhesive Films to Attack by Laboratory Rats," (ASTM D 1383) [5] .

When adhesives, paints, or similar 1 iquid materials are tested, the percentage of destruction of the uncoated blank should be the same as that for the coated material.

\section{A.9.5. Mold Growth Resistance}

Mildew is a dark fungus growth that thrives on paint films, wood, and other organic substrates in the presence of humid conditions. It is difficult to remove and is usually characterized by black spores resembling fly specks or long string-like fibers.

The growth of mold on interior walls and ceilings is usually enhanced by periodic or persistently damp indoor conditions. It can be reduced by providing adequate cross-flow ventilation.

As a health precaution, the finish of interior wall and ceiling surfaces should be resistant to the growth of fungi (mildew) indigenous to the particular geographic region. When materials are tested in accordance with the Federal Test Method for "Mildew Resistance" [6], there should be no evidence of mold growth. 
(Performance: Health and Safety, A.9.6)

\section{A.9.6. Dirt Collection Resistance}

The resistance of a coating to the collection or adherance of dirt is a desirable property to be considered in the selection of finishes. Primary factors affecting the adhesion of dirt are: 1) film density, 2) the chemical nature of components, and 3) the texture of finish.

\section{A.10. Performance: Durability and Stability*}

\section{A.10.1. Structural Integrity}

The structural components to be evaluated include walls, floor joists, wall studs, ceiling joists, and roof rafters.

The primary judgments concern the integrity of the total structure. If the dwelling unit does not conform to the FHA Standards or other applicable codes, a decision will have to be made either to make the needed structural repairs or to condemn the dwelling.

When the dwelling unit conforms to FHA Standards, the interior wall and surfacing materials should be evaluated to determine which available materials or systems would satisfactorily eliminate the leaded paint hazard and to select the most desirable solution.

\section{A.10.2. Scrape Adhesion}

Scrape adhesion is a measure of the bond between coatings and substrates. It is difficult to define precisely the adhesion of a surface covering material since this property is dependent upon many factors.

* These performance recommendations are intended for use as guidelines when applicable local code requirements are not available. 
(Performance: Durability and Stability, Table A-2)

Table A-2

Evaluation of Adhesion with Balanced Beam Scrape Adhesion Tester*

\begin{tabular}{|l|l|}
\hline Load Applied (Kg) & Rating \\
\hline $0.5-1.0$ & Poor \\
$1.5-2.5$ & Fair \\
$3.0-4.0$ & Good \\
$4.5-5.0$ & Very Good \\
Above 5.0 & Excellent \\
\hline
\end{tabular}

* Gardner Laboratory, Inc., Bethesda, Maryland, Bulletin No. SG-1605, Revised $10 / 64$. 
(Performance: Durability and Stability, A.10.2 continued)

The scrape adhesion of coatings may be evaluated by Federal Test Method for "Adhesion of Coatings with Scrape-Adhesion Apparatus" [7] (ASTM D 2197 "Standard Methods of Test for Adhesion of Organic Coatings" [8] is equivalent).

This method covers the determination of the adhesion of coatings of paint, varnish, 1 acquer, and related products when applied to flat panel sheet materials to a substrate. The values given in table A-2 for this method can be used to rate the scrape adhesion properties of materials.

\section{A.10.3. Impact Resistance}

In addition to structural functions, walls and ceilings divide a dwelling unit into habitable spaces. Normal usage of habitable spaces does not subject walls and ceilings to severe impact forces. However, accidental impact and abuse of surfaces do occur and the material used on a wall or ceiling must afford some degree of impact resistance.

A laboratory method suitable for evaluating coated surfaces is described in ASTM D 2794, "Resistance of Organic Coatings to the Effects of Rapid Deformation" [9]. This test procedure, which uses test panels, can be modified to include factory-finished coating systems on any substrate. When tested in accordance with ASTM D 2794, the impact force resisted by painted $3 / 8$ inch thick gypsum wallboard, without complete penetration of the wallboard, was found to be 20 inch $1 \mathrm{bs}$. This value represents the minimum force that should be reasonably resisted by any finished wall system. When materials demonstrate brittle fracture. 
(Performance: Durability and Stability, A.10.3 continued)

(cracking beyond the immediate test area), damage should not occur beyond an area bounded by a circle with a radius of 3 inches from the point of impact.

This criterion is a minimum that should be required for wall surfacing materials to be used up to a height of 56 inches which is the nominal height that can be reached by a six year old boy standing on the floor. Since upper wall and ceiling surfaces would not be subjected to the same abuse as lower wall surfaces the impact criteria for these surfaces need not be as severe.

\section{A.10.4. Abrasion Resistance}

An important property of surface coatings is their ability to withstand the abrasive forces of cleaning.

Abrasion resistance is a function of surface hardness, coating thickness, and cohesion of the coating material. Results of abrasion tests therefore can be interpreted as a measure of the durability of a coating as well as its ability to resist direct abrasive forces.

A practical test method for evaluating the resistance of interior coating materials to abrasion is outlined in the Federal Test Method for "Scrub Resistance" [10]. An acceptable coating of good durability should be capable of withstanding 1000 cycles of scrubbing.

\section{A.10.5. Moisture Resistance}

In areas such as 1 aundry rooms, bathrooms, and kitchens, special provisions should be made to provide surfaces that are resistant to frequent exposure to moisture and that form a barrier to the migration of water vapor. 
(Performance: Durability and Stability, A.10.5 continued)

Where optimum moisture resistance is considered necessary, the finish should have a maximum moisture vapor transmission of 1.2 perms* at $75^{\circ} \mathrm{F}$ when tested as outlined in ASTM Designation E 96, "Water Vapor Transmission of Materials in Sheet Form" [11]. The combination of the specified coating and recommended primer should have a moisture vapor transmission value of less than 1.0 perm.

Typical formulated paints considered appropriate for such a specialized function include:
a. Rubber-base paints
b. Epoxy paints
c. Urethane
d. Glaze coatings
e. Alkyd enamels

\section{A.10.6. Vibration Resistance}

Since building vibration problems have not been fully investigated, design criteria for covering up surfaces containing leaded paint in dwellings subject to continuous or intermittent vibration have not yet been established. When external sources of vibration are present near such a dwelling unit, engineering judgment must be relied upon to determine the installation techniques and the materials to be used.

\footnotetext{
* A perm is defined as the water vapor transmission rate of one grain of water vapor per square foot per hour per inch of mercury difference in vapor pressure.
} 


\section{A.10.7. Colorfastness}

Paints and other surface finish materials used to protect and decorate surfaces should retain their color for their intended 1 ifetime (a minimum of three years in the case of paints and a minimum of 15 years in the case of more permanent finishes such as those provided on factoryfinished products such as wood paneling, vinyl covered wallboard and similar products).

After accelerated weathering [12] for 200 hours, the color difference [13] for opaque finishes should not be greater than three units. For white paint the yellowness index difference [14] after 200 hours of accelerated weathering [12] should not exceed 1.5 units.

\section{A.10.8. Aging Resistance}

Field-applied coating-type surface finishing materials, such as paint, should have an expected serviceability life of three to seven years depending on the usage conditions to which they are subjected. More permanent surface finishing materials, such as factory finished wood paneling or plastic coated panels, should be capable of performing their intended function for 15 to 20 years without requiring major repair.

Commonly used materials that may require a final finish include plaster, gypsum board, plywood, hardboard, and similar materials. These types of substrates should perform satisfactorily for a minimum of 20 years when subjected to normal usage. Repair procedures should be limited to minor replacement of areas that have been exposed to unusual 
(Performance: Durability and Stability, A.10.8 continued)

abuse by occupants or areas that may have been damaged by excessive moisture caused by mechanical failure of water supply lines or waste removal systems. The material life spans mentioned above are based on the supposition that installation procedures as recommended by the manufacturer of a material have been followed.

Both prefinished wall systems of proven durability and innovative systems should meet the performance test requirements referred to in this report. Innovative systems should also be subjected to other test procedures that demonstrate their flexural, tensile and impact strengths. These properties should compare favorably with test results of conventional substrates that are known to perform satisfactorily.

\section{A.10.9. Adhesion of Leaded Paint}

If the leaded paint adheres tightly to a substrate and there is little likelihood of its becoming a hazard in the future, its removal is not imperative when it is outside of the reach of children, and in a location where deterioration due to water leaks, moisture, and other causes is not likely to occur, e.g., bedrooms as compared to kitchens and bathrooms.

When covering materials are to be applied with adhesives directly over paint, the paint must be tightly adhered and remain in this condition or the facings will subsequently delaminate.

Paint adhesion can be evaluated by using the cross-cut test method. Two sets of 11 parallel 1 ines, $1 / 16$ inch apart, are cut to intersect at 
(Performance: Durability and Stability, A.10.9 continued)

right angles, thus forming a grid of 100 squares, approximately $1 / 16$ inch by $1 / 16$ inch. Adhesion is measured by determining the sample surface area that is removed when a piece of masking tape is applied to the test grid and pulled off. The cuts are made just deep enough to go through the paint coating but not into the substrate surface to which it is applied. A razor knife can be used to cut the test grid with the aid of a template. In general, fragments of the coating along the scribe marks and/or where they intersect will be removed rather than discrete squares.

Paint is tightly adhered if less than $10 \%$ of the grid surface is removed in a random distribution over the entire grid and if 1 ess than $5 \%$ of the total grid surface area is removed from any single 5 square by 5 square area.

Scraping loose paint is not required when applying a facing with adhesives if less than $20 \%$ of the surface is removed in a random distribution over the entire grid or if 1 ess than $10 \%$ of the total surface area is removed from any single 5 by 5 square area. Two choices are available if the above criteria are not met. The surfaces can either be covered with a rigid material that does not require the use of adhesives, or loose paint can be removed. 
(Performance: Durability and Stability, A.10.10)

\section{A.10.10. Adhesive Durability and Stability*}

The adhesives used to 1 aminate covering materials to walls and other surfaces should be chosen carefully to ensure the long term durability and stability of the system.

Durability factors that should be considered include: compatibility with the materials that the adhesive is in contact with, bond strength, deterioration due to aging, and attack by moisture. Certification that an adhesive product meets the following requirements should be required before permitting its use.

a. The compatibility of adhesives, coatings and sealants with materials they come in contact with can be evaluated by following the procedures outlined in ASTM C 590 [15]. There should be no sign of substrate deterioration (corrosion, blistering, cracking, etc.) when tested as specified.

b. Adhesive bond strength can be evaluated by means of a static load test similar to that described in section 6.1 .3 of ASTM D 1779 [16]. Surfaces that will acutaliy be in contact with the adhesive should be duplicated for this test, if possible. If both the covering material and the substrate to which it is adhered are rigid board-type materials, samples of the configuration described in the above test method can be used.

* Adhesive test requirements are discussed in detail in this section since comprehensive specifications dealing with the requirements for wall covering adhesives could not be found in the literature. Test requirements given for adhesive performance are tentative, and thus subject to change. 
(Performance: Durability and Stability, A.10.10 continued)

When the covering material is flexible or semirigid, it should be firmly attached to a solid substrate with epoxy cement or mechanical fasteners before testing. If the covering is intended for use on a painted substrate, painted gypsum board, plywood, or a similar material should be used for one of the test discs. Adhesive spreading rates should be the same as those which would be used in actual installations.

After preparation, and before testing, the test specimens should be preconditioned for seven days at $50 \pm 4 \%$ relative humidity and $23^{\circ} \pm 2^{\circ} \mathrm{C}\left(73^{\circ} \pm 4^{\circ} \mathrm{F}\right)$ with no load attached.

Following the preconditioning phase, the test specimens should be suspended with weights added to the lower hook to bring the total load to $0.25 \%$ pound per square inch (psi), (including the weight of the lower disk and hook). The adhesive should be considered to have failed if any separation in the adhesive 1 ayer is noted within 28 days.

c. Deterioration of adhesives due to aging can be determined by using the tensile shear test procedure given in Commercial Standard 168-50 [17], which is similar to the one outlined in

* Note: With an adhesive contact area of $25 \%$ of the total surface area, an adhesive having a bond strength of $0.25 \mathrm{psi}$ is recommended for use with a load not to exceed $2-1 / 4$ pounds per square foot. Heavier materials can be supported by increasing the contact area of the adhesive used and/or by raising the bond strength of the adhesives used in proportion to the gain in weight. 
(Performance: Durability and Stability, A.10.10 continued)

Federal Test Method Standard No. 175, Method 1033.1-T [18] (a1so ASTM D 1002 [19]. Specimens should be prepared by bonding together two strips of 5-ply exterior grade plywood that is 1 inch wide by 4 inches 1 ong by $3 / 4$ inch thick.

The two plywood strips should overlap for an area of $2.0 \pm$ 0.1 square inches.

After preconditioning for 21 days at $23^{\circ} \pm 2^{\circ} \mathrm{C}\left(73^{\circ} \pm 4^{\circ} \mathrm{F}\right)$ and $50 \pm 4 \%$ relative humidity, the samples should be aged for seven days in a circulating air oven at $65^{\circ} \pm 2^{\circ} \mathrm{C}\left(149^{\circ} \pm 4^{\circ} \mathrm{F}\right)$ and a relative humidity of 1 ess than $10 \%$. The specimens should then be allowed to stand at $23^{\circ} \pm 2^{\circ} \mathrm{C}$ for one hour, and tested immediately.

The specimens should be broken in a suitable tensile testing machine at a rate of jaw separation of 2 inches per minute. The test samples should be held in the grips so that the outer 1.5 inches of each end are in contact with the jaws and so that their long axis coincides with the direction of applied force through the center line of the grip assembly. Separate blocks, the thickness of the adherents, should be used in the grips to insure that the adhesive bond is subjected to tensile-shear. The average tensile-shear value for 10 samples should be not less than 10 psi. 
(Performance: Durability and Stability, A.10.10 continued)

d. Moisture resistance should be considered if an adhesive is to be used in wet areas. Test specimens should be prepared and preconditioned as described in the aging test. Following preconditioning, the specimens should be immersed in water at $23^{\circ} \pm 2^{\circ} \mathrm{C}$ for 24 hours, then conditioned for 48 hours or more at $23^{\circ} \pm 2{ }^{\circ} \mathrm{C}$ and $50 \pm 4 \%$ relative humidity. The specimens should then be tested following the procedures outlined in the aging test. The average tensile-shear value for 10 samples should not be less than $10 \mathrm{psi}$.

\section{A.11. Performance: Acceptability}

\section{A.11.1. Washability}

Washability is a measure of the ability of finished surfaces to be cleaned. Coatings should be resistant to the retention of soil and the effects of soil removal.

Gloss and semigloss coatings can be evaluated for washability by following the procedures given in the Federal Test Method for "Washability of Paints" [20]. Flat coatings can be evaluated with the same test procedure if $85^{\circ}$ specular gloss [21] is measured instead of $60^{\circ}$, and the sponge is recharged after every 25 cycles until a total of 100 cycles has been run.

When tested as specified above, the soil shall be substantially removed without any exposure of the undercoat. The reflectance of the cleaned area shall not be less than $95 \%$ of the value measured on the 
(Performance: Acceptability, A.11.1 continued)

unsoiled area before test. The $85^{\circ}$ gloss shall be not greater than 15 units (flat coatings), and the $60^{\circ}$ gloss shall not increase more than $125 \%$ or 2 units, whichever is greater.

Usually, the higher the sheen, the greater the washability and durability. However, this does not mean that flat paints are unwashable. When properly formulated, low gloss, high density coatings can be very easily cleaned. Coatings that meet the above criteria should permit easy removal of stains and normal dirt accumulations. Minimal changes in the appearance and durability of the film should occur.

\section{A.11.2. Maintainability of the Surface}

Surface maintainability is a factor that should be considered when covering material selections are made. Ease of repair should be of primary concern in applications where the probability of damage is high. When exposure to damage is low, more latitude can be used in the selection of surface finish materials. Damage, e.g., localized indentations that may result from either intentional or accidental abuse, should be considered under maintainability. Major damage that would affect the structural integrity of the wall-ceiling system used would not be considered a surface maintainability problem.

Materials can be grouped into the following three maintainability classes:

Class I - field-painted substrates such as gypsum board, two-coat plaster, veneer plaster, plywood, and hardboard. 
(Performance: Acceptability, A.11.2 continued)

C1ass II - factory-finished gypsum board, plywood, hardboard, and fiberglass panels.

Class III - plain and reinforced cementitious coverings, resin base sheet material, spray-applied fiberglass reinforced plastics and other innovative systems.

Smooth installations of Class I materials would be the easiest and least expensive to repair. Powdered and premixed spackling compounds are readily available and putty knife applications of these materials to repair indentations, deep scratches and gouges are easily performed by semiskilled 1 abor. The repair areas $c$ an then be recoated with paint to complete the repair procedure. When textured surfaces of these materials are damaged, the repair procedures are complicated by the desirability to reproduce the surface texture and may require the services of skilled labor experienced in this kind of repair.

The repair of Class II materials is further complicated (when compared to textured $\mathrm{Cl}$ ass I surfaces) by the need to reproduce color and patterns as wel1 as texture on the damaged areas. Filler material must either be premixed to match the existing surface or tinted after filling. The filler material would necessarily vary in composition to be compatible with the surface being repaired. The repair of wood or simulated wood grain or patterned finishes that may be reproduced on sheet over1 ays would require skilled 1 abor. 
(Performance: Acceptability, A.11.2 continued)

Class III materials offer essentially the same problems as Class II materials concerning adhesion, color matching, and texture. An added disadvantage may be that repair procedures may either require the services of the material manufacturer's representative, or in the case of innovative systems adequate repair procedures may not have been fully developed.

\section{A.11.3. Acoustic Properties}

Consideration should be given to the acoustic properties of the walls and ceilings of a rehabilitated dwelling unit. The sound transmission class should be at least as high as it was before rehabilitation. Table A-3 can be used as a guide in establishing the transmission loss that should be specified. Sound transmission classes of construction materials can generally be determined by referring to material manufacturer's specifications or industry standards.

The minimum sound transmission class acceptable for intradwelling space dividers is 36 decibels (db).

\section{A.11.4. Color Reflectance}

Color plays an important role in the modern educational, recreational, and residential environment. It contributes to better vision, increased output, morale, safety, and moods of the inhabitants while protecting and decorating the surface.

Although the selection of color is a matter of personal preference, there are certain guidelines that should be followed. Better vision is promoted by selecting colors within the following reflectance range for the designated areas. 
(Performance: Acceptability, Table A-3)

Table A-3

Classification of Sound Insulating Properties of Partitions According to Their Average Transmission Loss*

\begin{tabular}{|c|c|c|}
\hline $\begin{array}{l}\text { Transmission } \\
\text { Loss of Wall }\end{array}$ & Hearing Conditions & Rating \\
\hline $\begin{array}{l}30 \mathrm{db} \text { or } \\
\text { less }\end{array}$ & $\begin{array}{l}\text { Normal speech can be understood } \\
\text { quite easily and distinctly } \\
\text { through the wall. }\end{array}$ & Poor \\
\hline 30 to $35 \mathrm{db}$ & $\begin{array}{l}\text { Loud speech can be understood } \\
\text { fairly well. Normal speech can } \\
\text { be heard but not easily under- } \\
\text { stood. }\end{array}$ & Fair \\
\hline 35 to $40 \mathrm{db}$ & $\begin{array}{l}\text { Loud speech can be heard, but } \\
\text { is not easily intelligible. } \\
\text { Normal speech can be heard } \\
\text { only faintly, if at all. }\end{array}$ & Good \\
\hline 40 to $45 \mathrm{db}$ & $\begin{array}{l}\text { Loud speech can be faintly heard } \\
\text { but not understood. Normal } \\
\text { speech is inaudible. }\end{array}$ & $\begin{array}{l}\text { Very good - rec- } \\
\text { ommended for di- } \\
\text { viding walls be- } \\
\text { tween apartments. }\end{array}$ \\
\hline $\begin{array}{l}45 \mathrm{db} \text { or } \\
\text { greater }\end{array}$ & $\begin{array}{l}\text { Very loud sounds, such as loud } \\
\text { singing, brass musical instru- } \\
\text { ments, or a radio at full } \\
\text { volume can be heard only } \\
\text { faintly or not at all. }\end{array}$ & $\begin{array}{l}\text { Excellent - rec- } \\
\text { commended for } \\
\text { band rooms, music } \\
\text { practice rooms, } \\
\text { radio and sound } \\
\text { studios. }\end{array}$ \\
\hline
\end{tabular}

* Diehl, J. R., Manual of Lathing and Plastering, p. 252, Gypsum Association Edition, Noble, New York (1965). 
(Performance: Acceptability, A.11.4 continued)

Recommended Reflectance Values [22]

Ceiling . . . . . . . . . . . . . . $65 \%$ to $85 \%$
Walls . . . . . . . . . . . . . . . . $35 \%$ to $65 \%$
Floors . . . . . . . . . . . . $10 \%$ to $20 \%$

There are many colors that produce particular effects, and proper use necessitates consideration of area, natural or artificial light, climate, and intended use. Primary factors in the selection of color should be attractiveness, preference, and functional advantages [23].

\section{A.11.5. Attachment Capability}

Walls and other surfaces should permit the installation of cabinets, shelves, lighting fixtures, pictures, etc. without requiring costly modifications.

\section{A.11.6. Appearance}

Appearance of the final finish reflects the skill of the craftsman as well as the quality of the applied finish. Proper use of coatings will provide a decorative surface that protects the substrate to which it is applied.

When paint-type coatings are used, each coat should be applied at proper consistency and brushed evenly, free of brush marks, sags, and runs. The paint should be applied so that overlapping on glass or hardware is avoided, and the film should be uniform in color and gloss.

The above qualities should also be required of other surface finish methods. 
[1] "Fire Protection," Chapter V, Minimum Property Standards for Multifamily Housing, FHA No. 2600, U.S. Department of Housing and Urban Development, pp. 123-155, Washington, D.C., February 1971.

[2] "USA Standard Specifications To Minimize Hazards to Children from Residual Surface Coating Materials," 266.1-1964, American Standards Association, New York, New York, 1964.

[3] "Building Planning," Chapter IV, Minimum Property Standards for Multifamily Housing, FHA No. 2600, U.S. Department of Housing and Urban Development, pp. 69-122, Washington, D.C., February 1971.

[4] "Susceptibility of Dry Adhesive Films to Attack by Roaches," D 1382 , ASTM Book of Standards, pt. 16, 1971.

[5] "Susceptibility of Dry Adhesive Films to Attack by Laboratory Rats," D 1383, ASTM Book of Standards, pt. 16, 1971.

[6] "Mildew Resistance," Method 6271.1, Federal Test Method Standard 14la, Paint, Varnish, Lacquer, and Related Materials; Methods of Inspection, Sampling, and Testing, (General Services Administration, Washington, D.C. 20405, September 1965).

[7] "Adhesion of Coatings with Scrape Adhesion Apparatus," Method 6303.1, Federal Test Method Standard 14la, Paint, Varnish, Lacquer, and Related Materials; Methods of Inspection, Sampling, and Testing, (General Services Administration, Washington, D.C. 20405, September 1965).

[8] "Adhesion of Coatings of Paint, Varnish, Lacquer, and Related Products," D 2197, ASTM Book of Standards, pt. 21, 1971.

[9] "Resistance of Organic Coatings to the Effects of Rapid Deformation," D 2794, ASTM Book of Standards, pt. 21, 1971.

[10] "Scrub Resistance," Method 6142, Federal Test Method Standard 141a, Paint, Varnish, Lacquer, and Related Materials; Methods of Inspection, Sampling, and Testing, (General Services Administration, Washington, D.C. 20405, September 1965).

[11] "Water Vapor Transmission of Materials in Sheet Form," E 96, ASTM Book of Standards, pt. 14, 1970.

[12] "Accelerated Weathering (Enclosed Arc Apparatus)," Method 6153, Federal Test Method Standard 14la, Paint, Varnish, Lacquer, and Related Materials; Methods of Inspection, Sampling, and Testing, (General Services Administration, Washington, D.C. 20405, September 1965). 
[13] "Color Difference of Opaque Materials Instrumental Measurement," Method 6123, Federal Test Method Standard 141a, Paint, Varnish, Lacquer, and Related Materials; Methods of Inspection, Sampling, and Testing, (General Services Administration, Washington, D.C. 20405, September 1965).

[14] "Yellowness Index," Method 6131, Federal Test Method Standard 14la, Paint, Varnish, Lacquer, and Related Materials; Methods of Inspection, Sampling, and Testing, (General Services Administration, Washington, D.C. 20405, September 1965).

[15] "Action on Substrates by Coatings, Adhesives, and Joint Sealers Used on or With Thermal Insulations," C 590, ASTM Book of Standards, pt. 14, 1970 .

[16] "Adhesive For Acoustical Materials," D 1779, ASTM Book of Standards, pt. 16, 1971.

[17] "Polystyrene Plastic Wall Tiles and Adhesives for Their Application," Commercial Standard 168-50, (Office of Industry and Commerce, U.S. Department of Commerce, 1958).

[18] "Shear Strength Properties of Adhesives Determined with Single-Lap Construction by Tension Loading," Method 1033, Federal Test Method Standard 175, Adhesives: Methods of Testing, (General Services Administration, Washington, D.C. 20405, November 1956).

[19] "Strength Properties of Adhesives in Shear by Tension Loading (Metal to Meta1)," D 1002, ASTM Book of Standards, pt. 16, 1971.

[20] "Washability of Paints," Method 6141, Federal Test Method Standard 14la, Paint, Varnish, Lacquer, and Related Materials; Methods of Inspection, Sampling, and Testing, (General Services Administration, Washington, D.C. 20405, September 1965).

[21] "Gloss, 85-Degree Specular (Sheen)," Method 6103, Federal Test Method Standard 14la, Paint, Varnish, Lacquer, and Related Materials; Methods of Inspection, Sampling, and Testing, (General Services Administration, Washington, D.C. 20405, September 1965).

[22] "Color Selection," Section H, Architectural Specifications and Product Descriptions, M. A. Bruder and Sons.

[23] "Color for Buildings," Department of the Army Technical Manual TM-5-807-7, Headquarters, Department of the Army, Washington, D.C., June 1968. 
ORM NBS-114A (1-71)

U.S. DEPT. OF COMM.

BIBLIOGRAPHIC DATA

SHEET

1. PUBLICATION OR REPORT NO.

2. Gov't Accession No.

NBS $\mathrm{TN}-770$

TITLE AND SUBTITLE

Hazard Elimination Procedures for Leaded Paints in Housing

5. Publication Date

May 1973

6. Performing Organization Code

8. Performing Organization

AUTHOR(S)

David Waksman, Leopold F. Skoda, Elizabeth J. Clark

PERFORMING ORGANIZATION NAME AND ADDRESS

NATIONAL BUREAU OF STANDARDS

DEPARTMENT OF COMMERCE

WASHINGTON, D.C. 20234

Sponsoring Organization Name and Address

Department of Housing and Urban Development

Washington, D.C. 20410

0. Pre iect/Task/Work Unit No.

4608400

il. Contract/Grant No.

IAA-H-34-71

13. Type of Report \& Period Covered

Final

14. Sponsoring A gency Code

SUP PLEMENTARY NOTES

- ABSTRACT ( A 200-word or less factual summary of most significant information. If document includes a significant bibliography or literature survey, mention it here.)

Methods currently used to control the hazard caused by leaded paints in housing vary in effectiveness from complete elimination of the hazard to a minimal effort that runs a high risk for recurrence of the hazard. A series of guidelines has been drawn up to acquaint municipal planners and other decision makers with the factors that should be considered in implementing a hazard elimination program. Formats are presented to describe attributes of the various methods that should be considered.

7. KEY WORDS (Alphabetical order, separated by semicolons)

Building material; housing; leaded paint; lead hazard elimination methods; lead paint poisoning; performance attributes.

8. AVAILABILITY STATEMENT

X UNLIMITED.

FOR OFFICIAL DISTRIBUTION. DO NOT RELEASE TO NTIS.

\begin{tabular}{|l|c|}
\hline $\begin{array}{c}\text { 19. SECURITY CLASS } \\
\text { (THIS REPORT) }\end{array}$ & $\begin{array}{c}\text { 21. NO. OF PAGES } \\
\text { UNCL ASSIF IED }\end{array}$ \\
\hline $\begin{array}{l}\text { 20. SECUR ITY CLASS } \\
\text { (THIS PAGE) }\end{array}$ & $\begin{array}{l}\text { 22. Price } \\
\text { UNCL ASSIFIED }\end{array}$ \\
$\begin{array}{l}\$ 1.25 \text { Domestic Postpaid } \\
\$ 1.00 \text { GPO Bookstore }\end{array}$ \\
\hline
\end{tabular}





\section{NBS TECHNICAL PUBLICATIONS}

PERIODICALS

JOURNAL OF RESEARCH reports National Bureau of Standards research and development in physics, mathematics, and chemistry. Comprehensive scientific papers give complete details of the work, including laboratory data, experimental procedures, and theoretical and mathematical analyses. Illustrated with photographs, drawings, and charts. Includes listings of other NBS papers as issued.

Published in two sections, available separately:

\section{- Physics and Chemistry (Section A)}

Papers of interest primarily to scientists, working in these fields. This section covers a broad range of physical and chemical research, with major emphasis on standards of physical measurement, fundamental constants, and properties of matter. Issued six times a year. Annual subscription: Domestic, $\$ 17.00$; Foreign, $\$ 21.25$.

\section{- Mathematical Sciences (Section B)}

Studies and compilations designed mainly for the mathematician and theoretical physicist. Topics in mathematical statistics, theory of experiment design, numerical analysis, theoretical physics and chemistry, logical design and programming of computers and computer systems. Short numerical tables. Issued quarterly. Annual subscription: Domestic, $\$ 9.00$; Foreign, $\$ 11.25$

\section{TECHNICAL NEWS BULLETIN}

The best single source of information concerning the Bureau's measurement, research, developmental, cooperative, and publication activities, this monthly publication is designed for the industry-oriented individual whose daily work involves intimate contact with science and technology-for engineers, chemists, physicists, research managers, product-development managers, and company executives. Includes listing of all NBS papers as issued. Annual subscription: Domestic, \$6.50; Foreign, \$8.25.

\section{NONPERIODICALS}

Applied Mathematics Series. Mathematical tables, manuals, and studies.

Building Science Series. Research results, test methods, and performance criteria of building materials, components, systems, and structures.

Handbooks. Recommended codes of engineering and industrial practice (including safety codes) developed in cooperation with interested industries, professional organizations, and regulatory bodies.

Special Publications. Proceedings of NBS conferences, bibliographies, annual reports, wall charts, pamphlets, etc.

Monographs. Major contributions to the technical literature on various subjects related to the Bureau's scientific and technical activities.

National Standard Reference Data Series. NSRDS provides quantitative data on the physical and chemical properties of materials, compiled from the world's literature and critically evaluated.

Product Standards. Provide requirements for sizes, types, quality, and methods for testing various industrial products. These standards are developed cooperatively with interested Government and industry groups and provide the basis for common understanding of product characteristics for both buyers and sellers. Their use is voluntary.

Technical Notes. This series consists of communications and reports (covering both other-agency and NBS-sponsored work) of limited or transitory interest.

Federal Information Processing Standards Publications. This series is the official publication within the Federal Government for information on standards adopted and promulgated under the Public Law 89-306, and Bureau of the Budget Circular A-86 entitled, Standardization of Data Elements and Codes in Data Systems.

Consumer Information Series. Practical information, based on NBS research and experience, covering areas of interest to the consumer. Easily understandable language and illustrations provide useful background knowledge for shopping in today's technological marketplace.

\section{BIBLIOGRAPHIC SUBSCRIPTION SERVICES}

The following current-awareness and literature-survey bibliographies are issued periodically by the Bureau:

Cryogenic Data Center Current Awareness Service (Publications and Reports of Interest in Cryogenics). A literature survey issued weekly. Annual subscription : Domestic, $\$ 20.00$; foreign, $\$ 25.00$.

Liquefied Natural Gas. A literature survey issued quarterly. Annual subscription: $\$ 20.00$.

Superconducting Devices and Materials. A literature survey issued quarterly. Annual subscription: $\$ 20.00$. Send subscription orders and remittances for the preceding bibliographic services to the U.S. Department of Commerce, National Technical Information Service, Springfield, Va. 22151.

Electromagnetic Metrology Current Awareness Service (Abstracts of Selected Articles on Measurement Techniques and Standards of Electromagnetic Quantities from D-C to Millimeter-Wave Frequencies). Issued monthly. Annual subscription: $\$ 100.00$ (Special rates for multi-subscriptions). Send subscription order and remittance to the Electromagnetic Metrology Information Center, Electromagnetics Division, National Bureau of Standards, Boulder, Colo. 80302.

Order NBS publications (except Bibliographic Subscription Services) from: Superintendent of Documents, Government Printing Office, Washington, D.C. 20402. 
U.S. DEPARTMENT OF COMMERCE

National Bureau of Standards Washington. D.C. 20234

POSTAGE AND FEES PAID

OFFICIAL BUSINESS

U.S. DEPARTMENT OF COMMERCE COM -215

Penalty for Private Use, $\$ 300$ 